\title{
Logistics Best Practices for Regional Food Systems: A Review
}

\author{
Anuj Mittal ${ }^{1}$, Caroline C. Krejci ${ }^{2, *}$ and Teri J. Craven ${ }^{1}$ \\ 1 Department of Industrial and Manufacturing Systems Engineering, Iowa State University, \\ 3004 Black Engineering Building, Ames, IA 50011, USA; amittal@iastate.edu (A.M.); \\ tjcraven@iastate.edu (T.J.C.) \\ 2 Department of Industrial, Manufacturing, and Systems Engineering, The University of Texas at Arlington, \\ Box 19017, Arlington, TX 76019, USA \\ * Correspondence: caroline.krejci@uta.edu; Tel.: +1-817-272-1891
}

Received: 15 December 2017; Accepted: 30 December 2017; Published: 11 January 2018

\begin{abstract}
The modern industrial food supply system faces many major environmental and social sustainability challenges. Regional food systems, in which consumers prefer geographically proximate food producers, offer a response to these challenges. However, the costs associated with distributing food from many small-scale producers to consumers have been a major barrier to long-term regional food system success. Logistics best practices from conventional supply chains have the potential to improve the efficiency and effectiveness of regional food supply chains (RFSCs). This paper provides a structured and in-depth review of the existing literature on RFSC logistics, including recommended and implemented best practices. The purpose of the review is to provide RFSC researchers and practitioners with convenient access to valuable information and knowledge derived from years of experimentation and research. This information will help to inform practitioners' implementation decisions and to increase researchers' awareness of the existing work on RFSC logistics, the unmet needs of practitioners, and topics that have not been fully explored, yielding insights into potential future directions for RFSC research. The overarching aim of the paper is to facilitate improvements in RFSC logistics, thereby improving regional food system viability.
\end{abstract}

Keywords: logistics; supply chain management; regional food systems; food hubs; sustainability

\section{Introduction}

The global food supply system provides consumers with convenient and consistent access to an extraordinary variety of food, irrespective of season or locale. Despite these benefits, consumers are increasingly seeking alternatives to the global system. In particular, demand for regionally-produced food has increased tremendously. In 2015, food that was produced and sold regionally by U.S. farms yielded $\$ 8.7$ billion in sales [1]. Some regionally-produced food is sold directly to consumers through farmers' markets, but most is distributed to consumers through retailers. In fact, the results of a 2015 survey indicate that $87 \%$ of consumers choose a supermarket based on its regional food offerings [2]. Consumers' motivations for buying regional food vary widely and are based on perceived benefits that include: Lower prices, food that is fresher, safer, and/or more nutritious than conventionally-produced food, reduced reliance on long-distance transport and fossil fuel consumption, and the ability to support the local economy [3-5]. Many consumers also value the ability to have face-to-face interactions with the farmers who produce their food. Such interactions facilitate transparency and trust-based relationships between producers and consumers [6,7].

Increased demand for regional food has the potential to greatly benefit small-scale farms (i.e., farms with annual income $<\$ 75,000)$, which account for $85 \%$ of all regional food providers [8]. In particular, direct-to-consumer sales (e.g., via farmers' markets) allow small-scale producers to 
offer lower volumes and set higher prices than mainstream distributors would accept. As a result, many federal, state, and local policymakers have begun to incorporate regional foods into programs designed to support small farmers and rural economies [9]. However, the scale and efficiency of direct-to-consumer marketing channels can be limiting-many consumers prefer the convenience of shopping for food at retail stores, and many farmers struggle to afford the high marketing and transportation costs associated with distributing their products at multiple farmers' markets [8,10].

For regional food systems to achieve their full potential, regional food producers must find ways of scaling up their operations to allow them to distribute their products to a greater number of consumers via institutional and retail channels. Such opportunities are increasingly available, with retailers, school districts, universities, healthcare facilities, and corporate cafeterias committing to sourcing more regionally-produced food [11-13]. The recent emergence of scale-appropriate logistics infrastructure for regional food systems has helped some producers to take advantage of these opportunities. In particular, regional food hubs provide logistics services to connect small-scale producers and institutional/retail buyers. A regional food hub is "a centrally located facility with a business management structure facilitating the aggregation, storage, processing, distribution, and/or marketing of locally/regionally-produced food products" [14]. A primary objective for food hubs is to support local economies by providing market opportunities for small-scale producers and treating them as valued business partners, rather than interchangeable suppliers [14].

However, most regional producers and food hubs do not have robust systems in place to support large-scale processing, aggregation, and distribution, and they often lack the necessary expertise, capital, and access to credit to acquire and implement these systems $[15,16]$. This lack of adequate logistics infrastructure has been a huge barrier to regional food system growth and success. Efforts to overcome this barrier have been primarily led by grassroots community groups, food policy councils, and local planners, who often have little expertise in food distribution logistics [17].

One approach to facilitating scaled-up logistics in regional food supply chains (RFSCs) is to implement best practices that have yielded high levels of efficiency and effectiveness in large-scale supply chains. Such practices include relationship development and coordination across the supply chain, efficient utilization of transportation and logistics infrastructure, implementation of accurate and reliable systems for food traceability, and data-driven demand planning and inventory management. Recommendations and guidance on logistics best practices for RFSCs are available in an extensive body of literature [18], but this literature is scattered and fragmentary. Most of the research on RFSC logistics has been communicated through case studies and technical reports written by various university extensions, non-profit organizations, and state and federal agencies. As a result, regional food practitioners have reported being overwhelmed by the continually growing body of knowledge [19].

There have been some efforts to organize and consolidate this research in reviews of recommended best practices and barriers to success, as well as examples of successes and failures [18-21]. Additionally, several bibliographies of publications on regional food systems have been compiled in an attempt to improve information accessibility for researchers [22-24]. However, the systematic study of RFSCs is still in its early stages [4,25]. As such, no systematic review has been conducted that integrates the available information on recommended RFSC logistics best practices, implementation examples of these practices by RFSC practitioners, and the associated benefits and challenges.

In an effort to fill this gap, this paper provides a structured and in-depth review of the existing literature on RFSC logistics. The purpose of the review is to provide researchers and practitioners with convenient access to valuable information and knowledge derived from years of experimentation and research. Practitioners will benefit from a greater awareness of logistics best practices that are available to them, as well as associated advantages and disadvantages, based on the experiences of other RFSC practitioners. Understanding these tradeoffs can help to inform their own decisions, for example, whether to buy or lease a truck (or perhaps neither). Furthermore, the analysis performed in this paper aims to increase researchers' awareness of the existing work on RFSC logistics, the unmet needs of practitioners, and topics that are not yet well understood and have not been fully explored, 
which may yield insights into potential future directions for RFSC research. The overarching aim of the paper is to facilitate improvements in RFSC logistics, thereby improving regional food system viability.

The paper is organized as follows: Section 2 describes the challenges associated with RFSC logistics management, with a focus on transportation, warehousing, and inventory management. These challenges were identified through a detailed review of peer-reviewed journal articles, technical reports by university extensions, conference papers, and book chapters. Section 3 summarizes best practices recommended in the mainstream supply chain literature to address the challenges described in Section 2. Section 4 describes the standard review method adopted in this paper. Using the best practices described in Section 3 as a framework, Section 5 provides a systematic review of recommended and implemented RFSC logistics best practices, as evidenced by case studies, university extension reports, and scholarly literature. Section 6 summarizes and analyzes the review and then discusses potential future directions for RFSC logistics research. Finally, Section 7 provides overarching conclusions from the review. Figure 1 shows the organization of the paper. 


\begin{tabular}{l} 
1. Introduction \\
2. Logistics Challenges Faced by RFSCS \\
$\begin{array}{l}\text { 3. Logistics Best Practices } \\
\text { Recommended for Conventional } \\
\text { Supply Chains }\end{array}$ \\
\hline
\end{tabular}

4. Review Method

5. Review of Recommended Best

Practices and Implementation

Examples from RFSCS

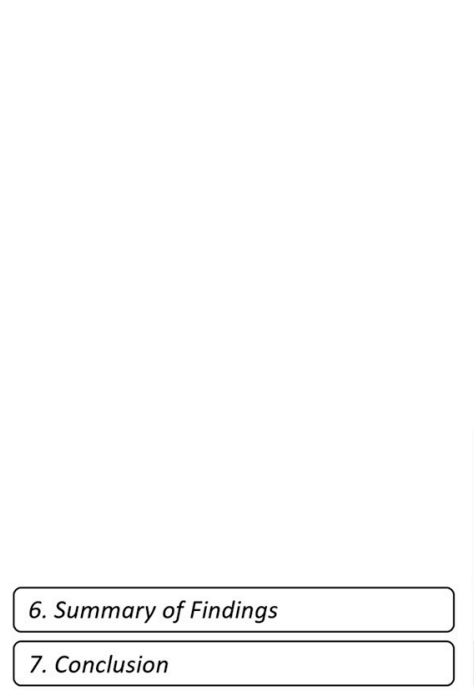

\begin{tabular}{|c|c|}
\hline & Identifying the Need For Systematic Literature Review on RFSC L \\
\hline 2.1 Transportation & 2.2 Warehousing \\
\hline 3.1 Transportation & 3.2 Warehousing \\
\hline 3.1.1 Efficient Vehicle Utilization & 3.2.1 Effective Labor Utilization \\
\hline 3.1.2 Backhauling & 3.2.2 Facility Location \\
\hline 3.1.3 Vehicle Selection & 3.2.3 Infrastructure Development \\
\hline 3.1.4 On-time and Frequent Deliveries & 3.2.4 Efficient Warehousing Policies \\
\hline 3.1.5 Third-party Logistics (3PL) & 3.2.5 Warehousing Collaboration and Resource \\
\hline $\begin{array}{l}\text { 3.1.6 Transportation Collaboration } \\
-\quad \text { Horizontal Collaboration } \\
-\quad \text { Vertical Collaboration }\end{array}$ & $\begin{array}{l}\text { Sharing } \\
-\quad \text { Horizontal Collaboration } \\
-\quad \text { Vertical Collaboration } \\
\end{array}$ \\
\hline
\end{tabular}

\section{Standard Review Method Adopted in the Paper}

\begin{tabular}{|c|}
\hline 5.1 Transportation \\
\hline $\begin{array}{l}\text { 5.1.1 Efficient Vehicle Utilization } \\
-\quad \text { Recommended Practices } \\
-\quad \text { Implemented Practices }\end{array}$ \\
\hline $\begin{array}{l}\text { 5.1.2 Backhauling } \\
-\quad \text { Recommended Practices } \\
-\quad \text { Implemented Practices }\end{array}$ \\
\hline $\begin{array}{l}\text { 5.1.3 Vehicle Selection } \\
-\quad \text { Recommended Practices } \\
-\quad \text { Implemented Practices }\end{array}$ \\
\hline $\begin{array}{l}\text { 5.1.4 On-time and Frequent Deliveries } \\
-\quad \text { Recommended Practices } \\
-\quad \text { Implemented Practices }\end{array}$ \\
\hline $\begin{array}{l}\text { 5.1.5 Third-party Logistics (3PL) } \\
-\quad \text { Recommended Practices } \\
-\quad \text { Implemented Practices }\end{array}$ \\
\hline $\begin{array}{ll} & \text { 5.1.6 Transportation Collaboration } \\
- & \text { Recommended Practices (Horizontal Collaboratior } \\
- & \text { Recommended Practices (Vertical Collaboration) } \\
- & \text { Implemented Practices (Horizontal Collaboration) } \\
- & \text { Implemented Practices (Vertical Collaboration) }\end{array}$ \\
\hline
\end{tabular}

\subsection{Warehousing}

5.2.1 Effective Labor Utilization

Recommended Practices
Implemented Practices

5.2.2 Facility Location

Recommended Practices

5.2.3 Infrastructure Development

Recommended Practices

Implemented Practices

5.2.4 Efficient Warehousing Policies

Recommended Practices

5.2.5 Warehousing Collaboration and Resource

5.2 .5 War
Sharing

Recommended Practices (Horizontal Collaboration)

Recommended Practices (Vertical Collaboration)

Implemented Practices (Vertical Collaboration)

Review Summary and Identified Research Gaps

Overarching Conclusion from the Review
2.3 Inventory Management

3.3 Inventory Management

3.3.1 Warehouse Inventory Management Systems

3.3.2 Inventory Tracking and Food Traceability

3.3.3 Demand Forecasting

3.3.4 Improved Supplier Reliability

3.3.5 Collaboration and Resource Sharing for

Inventory Management

Horizontal Collaboration
Vertical Collaboration

\subsection{Inventory Management}

5.3.1 Warehouse Inventory Management Systems Recommended Practices

5.3.2 Inventory Tracking and Food Traceability

Recommended Practices

5.3.3 Demand Forecasting

Recommended Practices

Implemented Practices

5.3.4 Improved Supplier Reliability

Recommended Practices

5.3.5 Collaboration and Resource Sharing for

Inventory Management

Recommended Practices (Horizontal Collaboration)

Recommended Practices (Vertical Collaboration)

Implemented Practices (Vertical Collaboration)

Figure 1. Paper organization. 


\section{Challenges in Regional Food Logistics}

Various definitions of the terms "logistics" and "supply chain management" exist in the literature. According to the Council of Logistics Management, logistics is a function that is contained within supply chain management and is defined as "that part of the supply chain process that plans, implements, and controls the efficient flow and storage of goods, services, and related information from the point of origin to the point of consumption in order to meet customers' requirements" [26]. According to [27], logistics includes warehousing, transportation, management of materials and information, and integration of logistics operations for the entire supply chain, whereas supply chain management merges marketing and manufacturing with distribution functions to improve competitive advantage. With respect to agriculture and food systems, logistics includes production planning and the movement of food products from producers to consumers, including processing, storage, handling, and packaging [28].

Based on the accepted definitions available in the existing literature, this paper broadly defines the scope of logistics to include transportation, warehousing, and inventory management [29-33]:

- Transportation: The movement of inventory from point to point in a supply chain.

- Warehousing: Activities involving the physical locations where inventory is stored, retrieved, assembled, and packed for distribution.

- Inventory management: Monitoring and deciding how much inventory to stock, what is in stock, and how inventory should be stored.

Effective logistics management requires sufficient infrastructure to support consistent deliveries of the right product, in the right quantity, in the right condition, to the right place, at the right time, for the right cost [34]. However, the logistics infrastructures of food supply chains are often not as developed as the supply chains of other industries, such as automotive or electronics [35]. This is especially true for RFSCs, in which distribution tends to be fragmented and less efficient than the centralized distribution networks of conventional food systems [28]. As a result, RFSCs commonly struggle with a variety of challenges in transportation, warehousing, and inventory management.

\subsection{Transportation}

Supply chains in every industry face a variety of transportation-related challenges, including capacity shortages, empty backhauling, issues with security and contamination, and concerns over environmental impacts and non-renewable energy consumption [36]. While regionally-produced food travels much shorter distances from farm to consumer than food that is distributed via conventional supply chains, RFSC transportation is typically much less efficient, due to the economies of scale that can be achieved with long-distance freight movement of full truckloads [37]. In fact, gains in fuel efficiency per unit of product hauled can cancel out the effects of longer transport distances [9]. This is particularly true for producers of specialty crops and niche food products-managing their movement from farm to market is much more complex and expensive than distributing conventional farm products. The smaller volumes and the necessity of keeping niche products separate from bulk commodities add to the cost of handling and shipping [38].

Many of the greatest logistical inefficiencies associated with regional food freight occur at the beginning and end of the supply chain, where numerous short but indirect first/last-mile hauling routes increase the per-unit hauling cost [37]. Small farmers often use their personal trucks or vans, rather than commercial carriers, for this purpose [39]. This requires the use of many small vehicles transporting low volumes, for which the balance between fuel used and volume transported is not favorable [40]. For example, a study on an RFSC in Sweden found that the average load rate was less than $50 \%$ [41].

RFSCs are also typically disaggregated and not vertically integrated [42], which can lead to coordination challenges. For example, a lack of coordination between transportation providers and 
small producers can cause problems when products are not packed and ready for a scheduled pickup, or when there is no one available at the farm to load products on the truck. Poor transportation coordination can also be problematic for producers who provide their own transportation. For example, when deliveries to a retailer or food hub warehouse are not properly scheduled, numerous producers may arrive at the same time, causing traffic congestion and delays [37].

\subsection{Warehousing}

The wide variety of products that are distributed through RFSCs presents a tremendous warehousing challenge. In particular, safely and efficiently handling and storing a large number of stock keeping units (SKUs) that may have product-specific cold storage requirements and varying degrees of perishability can be very difficult and expensive [43]. However, small-scale farmers and food hubs generally do not have access to sophisticated physical warehousing infrastructure (i.e., washing, cooling, packing, and storage facilities) [44]. Moreover, the physical infrastructure developed to facilitate high-volume transactions through conventional food supply chains can be inefficient and impractical when applied to regional food distribution. Unfortunately, infrastructure that is at an appropriate scale for small-scale producers is largely unavailable, which is a major challenge for RFSCs [45-47]. Therefore, new RFSC-specific warehousing infrastructure and supply chain models are needed to support efficient logistics for larger volumes of regional food products [48-50].

Warehousing labor availability is another major operational challenge for RFSCs. Out of 79 U.S. regional food hubs surveyed, 41 indicated labor availability as a barrier to growth [17]. Nine of these food hubs also emphasized that dependence on volunteer labor was a significant challenge. While volunteer labor helps to reduce costs, operational efficiency and consistency tend to suffer, due to a lack of training and inconsistent commitment [51].

\subsection{Inventory Management}

Balancing demand and supply is a major challenge for RFSCs. In fact, this was the most frequently cited challenge in interviews with U.S. food hub operators, primarily because demand is greater than what their regions are able to supply [52]. Regional food retailers in Michigan and Illinois have indicated that a lack of consistent supply has negatively impacted their sales $[53,54]$. This imbalance in supply and demand is partly a result of poor coordination between marketing and crop production, with respect to demand planning and inventory management [42]. Seasonal fluctuations in regional food availability are another major factor; in many regions, there is a shortage of supply in the winter months [55].

Another major inventory management challenge for RFSCs involves food traceability. One of the greatest perceived advantages of RFSCs is their ability to provide customers detailed information about product sourcing and production methods, due to their comparatively shorter supply chain structure [56]. Simply labeling products as 'regional' is insufficient, because customers often want to know which specific farm produced the food that they are purchasing. However, food hubs often struggle to maintain farm identity along the supply chain [52], because small-scale farmers will often combine their products with those of other farmers to make processing and shipping more economical [4].

\section{Logistics Best Practices}

Much of the existing research on RFSCs suggests that they should adopt conventional supply chain practices for their long-term growth and sustainability [57]. Such practices have the potential to reduce warehousing and transportation costs and improve the ability of RFSCs to meet growing consumer demand for regionally-produced food. In general, best practices in logistics are applicable to a wide variety of organizations, irrespective of industry, channel position, or size [58]. However, it is not clear how readily these practices translate to RFSCs. This section describes best practices that 
have been recommended for mainstream supply chains to address the logistics challenges that RFSCs commonly face, as described in Section 2.

\subsection{Transportation}

Best practices for maximizing transportation efficiency in supply chains include efficient vehicle utilization, reducing empty backhauling, appropriate vehicle selection, frequent and timely deliveries, leveraging the services of third-party logistics providers, and developing transportation collaborations.

\subsubsection{Efficient Vehicle Utilization}

Increasing vehicle load rate is one of the most important activities that an organization can undertake to reduce its carbon footprint, increase its logistics efficiency, and reduce transportation cost, since most shipments are less-than-truckload [29,59]. Maximizing vehicle load rates requires optimal routing and scheduling [60]. For example, by consolidating delivery routes and reducing the number of required stops, Kraft Foods improved its company-wide fuel efficiency by seven percent [29]. Similarly, a study in Serbia identified that optimizing delivery vehicle routing could yield a $20 \%$ reduction in transportation costs and associated emissions [61]. However, a systems view of the problem is essential-a case study on waste collection in Finland demonstrated that significant cost savings could be achieved by optimizing the routes and schedules of the entire fleet, rather than individual vehicles [62]. Strategic design of the distribution network structure is also critical. For example, having customers pick up their orders at a designated location can improve vehicle load rate, but providing last-mile delivery can be nearly as efficient if customer orders are sufficiently large [63].

Efficient vehicle utilization can be achieved through the use of a transportation management system (TMS) [59]. TMS software automates many key transportation functions, including optimal carrier selection, load building, fleet management, routing and scheduling, and freight audit payment. Although expensive, the return on investment for a TMS is generally less than a year, depending on the size and revenue of an organization [59]. For example, Coca-Cola implemented a TMS to determine optimal vehicle loads and routes, given distributors' volume, frequency, and delivery time window constraints. This system yielded an annual savings of $\$ 45$ million and significant improvements in customer service [64].

\subsubsection{Backhauling}

Backhauling, which involves carrying goods on return trips, rather than returning with empty trucks, can significantly improve vehicle load rates [65]. For example, after delivering products to a distributor, an empty truck can be routed to a nearby vendor to pick up raw materials [29]. By reducing the number of empty trips, backhauling increases overall fleet efficiency and reduces transportation costs for suppliers and customers, as well as help reducing environmental impacts $[29,66]$.

\subsubsection{Vehicle Selection}

Fleet management (i.e., determining fleet size and vehicle types, sizes, and ownership) significantly affects the percentage of empty hauls and overall transportation efficiency [67]. In particular, fuel consumption depends on vehicle type-large and/or refrigerated vehicles tend to have very low fuel efficiency [68]. Therefore, selecting appropriate vehicle types and sizes to meet supply chain objectives is critical. Adopting vehicles that use alternative or hybrid fuel technology can also reduce transportation costs and adverse environmental impacts [29,69].

Vehicle ownership is another major determinant of transportation efficiency. Leasing a vehicle allows organizations to avoid up-front investment. However, purchasing a vehicle can be less costly in the long run, depending upon the terms and conditions of the leasing contract (e.g., interest rate, down payment, and payment period) [70]. Maintenance costs, which tend to increase sharply after three years of vehicle usage, are an important consideration, as well as the risk of mechanical breakdowns, which can result in lost sales and dissatisfied customers [71]. In this regard, leasing can be beneficial, 
because it is generally the responsibility of the leasing company to provide alternate arrangements while the leased vehicle is being serviced [72].

\subsubsection{On-Time and Frequent Deliveries}

Customers highly value on-time deliveries, which tend to encourage repeat business [73]. On-time deliveries also facilitate effective and efficient cross docking by reducing waiting times for outbound trucks [74]. Additionally, frequent deliveries benefit customers by increasing product availability and freshness. However, frequent deliveries of small quantities can depress vehicle load rates, creating a financial burden for suppliers and distributors [66].

\subsubsection{Third-Party Logistics (3PL)}

A third-party logistics provider (3PL) is an organization that manages one or more logistics processes or operations (typically transportation or warehousing) for another company [33]. 3PL providers integrate multiple customer loads using sophisticated software to improve load rates and enable product traceability $[75,76]$. 3PLs can also provide aggregated information for many small suppliers in a single location, thereby reducing customers' search costs and eliminating the need for suppliers to invest in information infrastructure [31]. Many organizations have successfully outsourced some or all of their logistics operations to 3PLs, including Kimberly-Clark, which used a 3PL to satisfy retailers' delivery frequency requirements and significantly reduced its distribution costs [77].

\subsubsection{Transportation Collaboration}

Successful supply chains rely on long-term strategic collaborations that enable participants to work together to create an effective and efficient transportation system [78-80]. A survey of 286 companies revealed that collaboration was the most important transportation practice in driving their supply chain improvement [59]. There are two types of collaboration in logistics: Horizontal and vertical.

Horizontal collaboration-Horizontal collaboration occurs between organizations in different supply chains to better utilize assets and reduce overall costs [81,82]. In horizontal collaboration, organizations cluster their logistics activities and assets (e.g., through shared transportation and processing facilities) to improve efficiency and reduce environmental load [33]. Examples of horizontal collaboration in transportation include shared consolidation centers, joint trucking routes, and optimization of the entire transportation network across multiple competing supply chains for maximum transportation efficiency [82]. Effective horizontal collaboration between Nestle and United Biscuits resulted in fewer empty truck runs and eliminated 280,000 truck kilometers from the roads, reducing fuel consumption and $\mathrm{CO}_{2}$ emissions by 85,000 liters and 223 tons, respectively [77]. However, effective horizontal collaboration requires organizations to overcome significant challenges, including technological barriers and insufficient trust between coordinating partners [83].

Vertical collaboration-Vertical collaboration occurs between entities belonging to the same supply chains, either upstream (i.e., with suppliers), downstream (i.e., with customers), or internally across functions in an organization [82]. It can be facilitated through information exchange via interconnected system between successive partners in a supply chain [33]. Vertical collaboration in transportation is necessary to optimize a supply chain's transportation network, thereby reducing costs, improving service levels, and improving supply and delivery reliability $[30,81,82]$. For example, real-time sharing of information between distributors and retailers will enable them to identify delivery problems as they occur. This will improve the retailers' customer service levels and the distributors' transportation network planning.

\subsection{Warehousing}

Best practices for maximizing warehouse/distribution center productivity include effective labor utilization, optimized facility location selection, adequate infrastructure development, efficient and 
effective storage, picking, and packing policies, and collaboration and resource sharing within and outside the supply chain for warehousing activities.

\subsubsection{Effective Labor Utilization}

Inadequate employee training can result in a variety of negative outcomes, including poor man-hour utilization, worker frustration, and frequent turnover [84]. Therefore, implementing effective training programs is critical to success in warehousing operations. Properly training warehouse employees yields increase in operational efficiencies, as well as improved service levels $[59,85]$. In particular, cross-training workers to enable them to undertake a wider variety of tasks improves labor scheduling flexibility and can also lead to increased worker satisfaction and retention $[86,87]$.

\subsubsection{Facility Location}

Determining the optimum number and locations of warehouses is critical for logistics efficiency [59]. While transportation and inventory decisions can be changed relatively frequently without negative consequences, location decisions are often long-term and directly affect labor costs, transportation costs, and inventory holding costs, as well as many indirect costs, such as taxes [88]. Facility location decisions depend on access to markets and suppliers, competitor locations, government and tax regulations, environmental factors, labor availability, and transportation and utilities services [89]. Service quality and customer responsiveness are also important considerations-being located near major customer bases enables warehouses to provide just-in-time, smaller, and more frequent shipments to customers [90].

\subsubsection{Infrastructure Development}

Best-in-class companies invest significantly in infrastructure (e.g., technology and facilities) to improve the performance of their supply chains [91]. For food supply chains in particular, inadequate infrastructure can result in variable product quality, unreliable supply, and insufficient storage capacity [92], whereas investment in appropriate infrastructure (e.g., refrigeration) can improve product handling and storage, which reduces post-harvest losses [93].

\subsubsection{Efficient Warehousing Policies}

Order picking from warehouse storage locations to fulfill customer orders is labor-intensive and is therefore the costliest activity in most warehouses [94]. Therefore, an optimal warehouse layout and the use of effective and efficient storage and picking policies can significantly reduce material handling costs [59]. Designing a warehouse layout involves decisions regarding the relative locations of departments (e.g., receiving, picking, storage, sorting, and shipping), the appropriate number of picking blocks, and the length and width of aisles in each block, with an objective of minimizing overall warehouse operating costs [95].

Packaging provides opportunities for cost savings and improved sustainability throughout the supply chain [96]. Optimal packaging and pallet patterns can reduce materials usage, increase space utilization in the warehouse and on trucks, and reduce the amount of material handling required. The result is less packaging waste, greater vehicle load rates, and improved handling in the warehouse. This efficiency directly translates into less impact on the environment [97]. In the fresh food supply chain, the development of modified-atmosphere packaging lengthens the best-before-date and is often combined with sensors and tracking devices to facilitate traceability [33].

\subsubsection{Warehousing Collaboration and Resource Sharing}

Horizontal collaboration-Sharing warehousing and/or production capacity with other organizations can significantly reduce operational costs in a supply chain [81]. Horizontal collaboration 
in warehousing can also be extended to joint infrastructure development, which can reduce the need and risk of high up-front investment cost.

Vertical collaboration-Vertical collaboration in warehousing is important for reducing errors in inventory placement and order assembly, as well as facilitating cross-docking [98]. Cross-docking involves moving inbound material directly from receiving to shipping without placing it into storage locations. The items are unloaded, sorted by destination, and then reloaded onto outbound trucks. By eliminating storage and picking, cross-docking significantly reduces inventory and operational costs [59]. Cross-docking also prevents overstocking and reduces the risk of loss and damage of stored goods [99]. For example, Goodyear's transition from traditional warehousing to cross-docking increased their service levels to $96 \%$ and decreased operational costs by more than $12 \%$ [100]. However, successful cross-docking requires synchronization of the arrival times and capacities of inbound and outbound trucks. Many organizations use a hybrid combination of warehousing and cross-docking to take advantage of both approaches [101].

\subsection{Inventory Management}

Best practices in inventory management include implementing warehouse inventory management systems, using inventory tracking systems, matching supply with demand through demand forecasting, improving supplier reliability, and collaborative inventory management.

\subsubsection{Warehouse Inventory Management Systems}

An inventory management system allows buyers to coordinate with suppliers and accurately evaluate, order, and update inventory. In particular, e-sourcing - the use of electronic marketplaces for purchasing, rather than emails and spreadsheets-improves the speed and efficiency of procurement [59]. Furthermore, integrating the inventory management system with a buyer's material requirements planning (MRP) system can assist in making efficient long-range demand planning, purchasing, scheduling, and inventory management decisions [102].

\subsubsection{Inventory Tracking and Food Traceability}

Inventory tracking within a warehouse is best performed through the use of a warehouse management system (WMS). A WMS is a software application that interfaces with supply chain planning, order management, enterprise resource planning, and the TMS. It tracks the location of items by purchase order, bar code, lot number, or other identification system, such as RFID [59]. RFID tags have recently been introduced in the food supply chain by many large retailers (e.g., Walmart, Tesco, and Metro) at the pallet level. Using such tags provides significant logistical benefits, since the tracking of those items does not require human intervention [33]. In food supply chains, product traceability is critical for food safety, enabling timely product recalls and determination of liability [103].

\subsubsection{Demand Forecasting}

Accurate demand forecasting is one of the most important and most challenging measures of supply chain proficiency [59]. Demand planning involves collecting and analyzing historic sales and inventory data and then sharing this forecast information upstream and downstream in the supply chain [104]. Collaborative forecasting and replenishment reduce inefficiencies that result from multiple uncoordinated forecasts (i.e., the bullwhip effect) [105]. However, establishing sufficient trust between organizations and implementing appropriate technology for information sharing can be significant barriers [105].

\subsubsection{Improved Supplier Reliability}

Consistent supplier reliability is critical for supply chain success, because inventory availability significantly impacts customer satisfaction and loyalty [106,107]. Reducing supply uncertainty through 
improved supplier reliability can help organizations to match supply and demand, thereby increasing inventory availability and supply chain responsiveness. This is particularly important with suppliers of perishable goods [108]. Technological advances can help to improve supply reliability. For example, Gillette adopted RFID technology to monitor the flow of its products from distribution centers to retail stores and found that sales from RFID-enabled stores were 19\% higher than stores that did not use it due to less out-of-stocks [109].

\subsubsection{Collaboration and Resource Sharing for Inventory Management}

Horizontal collaboration-Group purchasing is a typical method of horizontal collaboration in inventory management [81]. Group purchasing can potentially lead to lower prices of products for collaborating organizations due to economies of scale, as well as give them an access to purchase goods which they could have not done alone due to volume constraints.

Vertical collaboration-Upstream vertical collaboration in inventory management includes supplier development and planning, production scheduling, and vendor managed inventory (VMI). Downstream vertical collaboration includes customer relationship management, collaborative demand planning, and demand replenishment [83]. Strong vertically collaboration and information sharing throughout the supply chain (both upstream and downstream) can help organizations reduce demand variability, improve forecast accuracy, and reduce inventory levels $[30,110]$. Because owning inventory involves carrying costs, keeping inventory levels to a minimum is critical for supply chain success. Inventory levels can be significantly reduced through the use of just-in-time (JIT), in which items are replenished just as they are required [111]. In particular, implementation of an electronic data interchange (EDI) system facilitates continuous electronic flow of consumer sales data and inventory management information between retailers and suppliers [112]. For example, Walmart shares real-time demand information electronically with its suppliers, who use this information to replenish inventory. The system results in less inventory, lower costs, and the ability to pass on these savings to customers [34].

\section{Review Method}

A standard three-step process was followed to conduct the systematic literature review, including planning the review, conducting the review, and reporting and dissemination [113].

In the planning stage, the Leopold Center for Sustainable Agriculture was contacted to obtain information about institutions and research centers in the U.S. that are conducting research on RFSCs. Information from the Leopold Center helped to establish connections with coordinators from the Sustainable Agriculture Research and Education (SARE) Program and researchers at the Wallace Center at Winrock International, which is a non-profit organization that is focused on social, agricultural, and environmental issues in the U.S. Based on recommendations from SARE coordinators, the Regional Food Systems group at Michigan State University and the Center for Environmental Farming Systems at North Carolina State University were contacted, as well. The inputs from these research centers and institutions helped to determine 12 major sources of technical reports in the area of regional food system logistics, as shown in Table 1 . The technical reports from these organizations were written by notable regional food system researchers, and many have been peer reviewed. Therefore, these reports are considered to be nationally credible. Reports available through March 2016 from the sources listed in Table 1 have been considered for review in this paper. 
Table 1. Sources of technical reports.

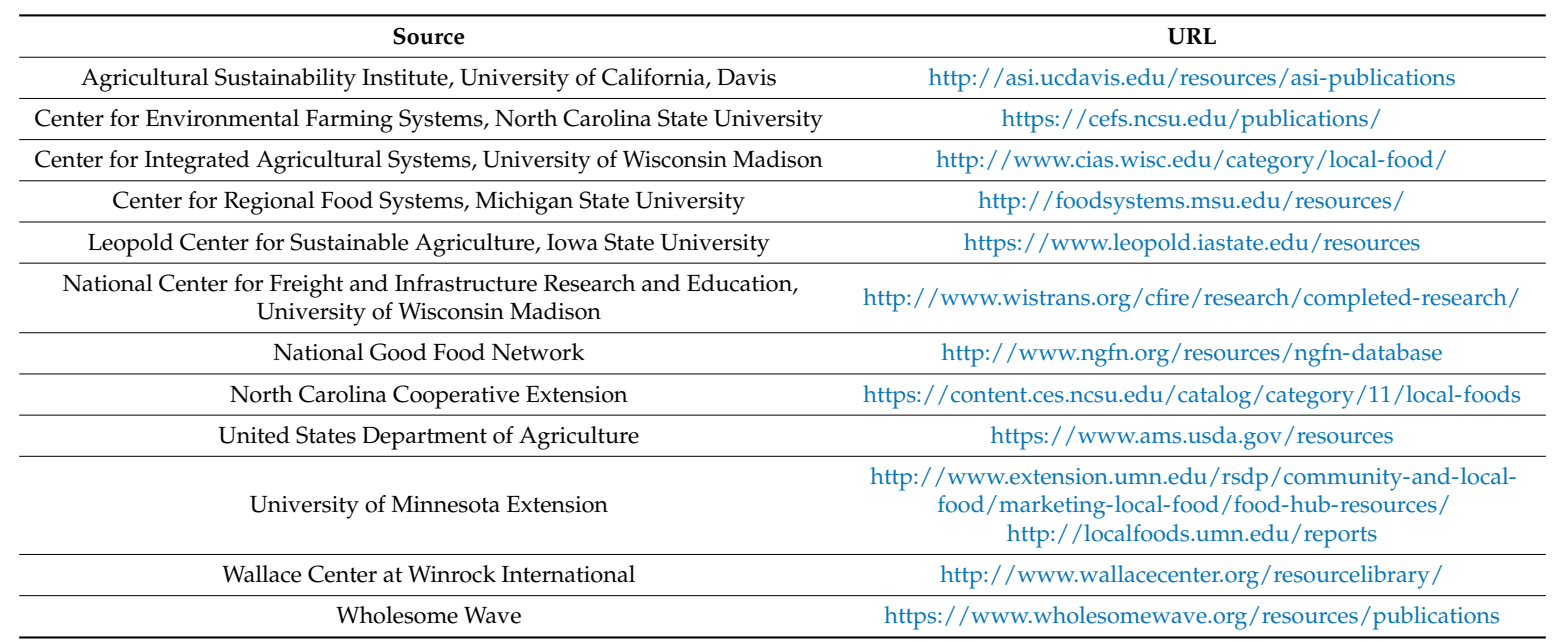

Peer-reviewed journal articles published between 2006 and 2016 (through February) that discuss best practices in RFSC logistics were also reviewed. The Scopus database was used to search for journal articles using a specific set of keywords, which are listed in Table 2. Scopus covers a broad range of journals and is widely accepted by the scientific community for structured literature reviews [114]. Articles were shortlisted based on combinations of keywords, a technique that is widely practiced in literature reviews that are published in reputed journals [115-117]. Every possible combination of keywords was used, resulting in an exhaustive search process. Table 2 provides the logic that was used to generate these combinations.

Table 2. Keyword set used for shortlisting journal articles in the Scopus database ("**" is used as an operator for truncated search process).

\begin{tabular}{ccccc}
\hline Keyword 1 & Boolean & Keyword 2 & Boolean & Keyword 3 \\
\hline food & AND & $\begin{array}{c}\text { region * } \\
\text { local } \\
\text { sustainab * }\end{array}$ & AND & $\begin{array}{c}\text { supply chain } \\
\text { logistics } \\
\text { value chain }\end{array}$ \\
\hline
\end{tabular}

In all, total 672 technical reports, journal articles, and case studies were reviewed. A total of 106 technical reports and 28 journal articles were determined to be the most relevant, and they were included in this paper. The flowchart in Figure 2 shows the literature search and screening process adopted in this study as per PRISMA guidelines. 


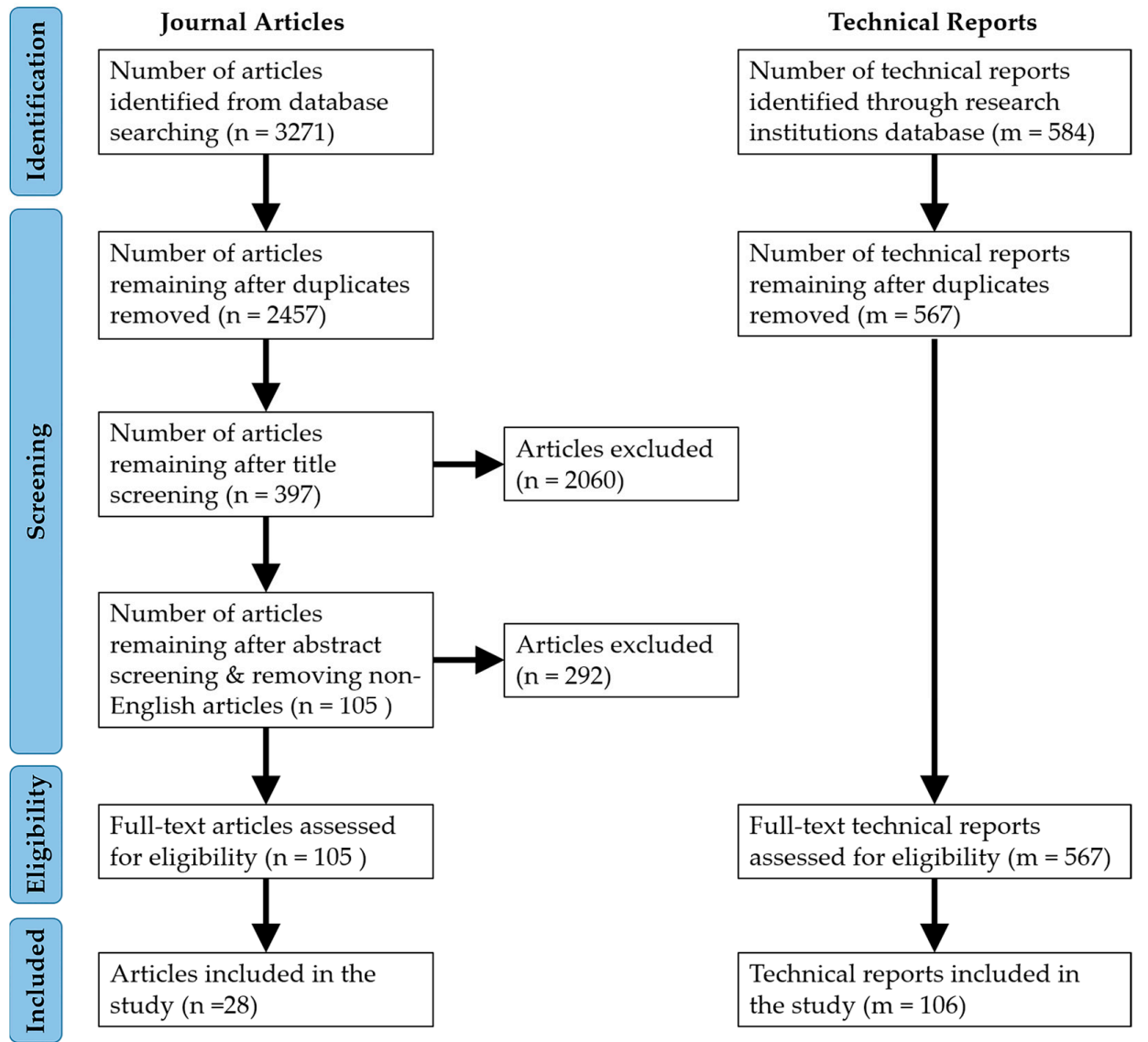

Figure 2. Flowchart of literature search and screening process.

\section{Best Practices in Regional Food Systems Logistics}

This section provides a systematic review of the literature on recommendations and implementation examples of logistics best practices in RFSCs. The focus of this review is restricted to the best practices that have been shortlisted in Section 3.

\subsection{Transportation}

This sub-section describes recommendations on the six transportation best practices by RFSC researchers, as well as implementation examples of these practices by RFSC practitioners.

\subsubsection{Efficient Vehicle Utilization}

Recommended practices - Route optimization and vehicle load rate maximization can help RFSC participants to reduce their fuel consumption and benefit from economies of scale [118]. Although regional food is not transported over long distances, RFSC transportation can consume more fuel than conventional food supply chains, as a result of inefficient collection and delivery processes $[4,8,119]$. RFSCs have low "food miles", but product aggregation to achieve large load sizes is necessary to yield highly fuel-efficient distribution systems $[9,120]$.

The Michigan Food Hub IT Platform Feasibility Study recommends the use of routing software that provides distribution route visibility, schedules, and product availability along each route and enables the creation of new routes [121]. To maximize load rates, RFSCs should also consider implementing Global Data Synchronization (GDS), which provides universal product codes and information-sharing standards for suppliers, distributors, and customers [122]. GDS improves the accuracy of information (e.g., product weights) throughout the supply chain. Having accurate product 
weights allows trucks to be filled as fully as possible without exceeding Department of Transportation weight limits. Although route planning is easier with software, the associated costs can be prohibitive for small organizations, which have fewer trucks and stops to consider [123]. Therefore, increased availability of affordable routing software that is tailored to the specific needs of RFSCs could greatly benefit such organizations [124]. However, if affordable software are unavailable, simple guidelines that leverage expert judgment may be appropriate. For example, in order to run cost-efficient routes with fully-loaded trucks, food hubs should plan their deliveries according to seasonal supply and focus on serving nearby customers when supply is low [125].

Implemented practices-Because they are generally small-scale organizations, most RFSC participants do not use sophisticated software for transportation routing. Instead, they tend to rely on expert knowledge and informal heuristics. For example, the employees of Local Harvest Supply, a regional food distributor in Coralville, Iowa, use their personal knowledge of roads, traffic, and past transportation decisions to plan their deliveries [123]. To maximize its load rates, Keewaydin Organics, a farm and regional food distributor in Viola, Wisconsin, uses small trucks to deliver products to an aggregation point and then makes long/large market hauls with a larger truck [126]. Keewaydin also uses Google Maps and regional knowledge to determine the most efficient routes [123]. The Purchase Area Aquaculture Cooperative, a farmer cooperative in Kentucky, also uses different types of vehicles for different kinds of deliveries. Their system uses a leased truck to make small deliveries directly to customers, and distributors are hired to handle large deliveries [127]. Some RFSCs have also increased vehicle utilization through distribution network design. All Natural Beef Cooperative, a natural beef co-op in Kansas, sells regionally-produced beef to Balls Food Stores, a grocery retailer in Kansas [128]. Originally, the cooperative shipped products from its processing facility to individual Balls Food's retail outlets, which required the use of multiple refrigerated trucks and labor to load and transport the meat. To address these issues, Balls Food now operates a hub-and-spoke distribution network in which products are brought from various regional producers to a central warehouse, where they are unloaded, repacked, and reloaded onto trucks and are then shipped to individual stores. This new network structure has reduced the number of deliveries to the grocery stores, thereby decreasing overall operational costs. It has also helped farmers reduce their transportation costs by providing them with a single delivery point [128]. However, Balls Food's central warehouse lacks sufficient cold storage capacity for All Natural Beef Cooperative's products, so the cooperative decided to open its own regional meat distribution facility [128].

A food hub in the UK uses a different strategy-it requires its customers to pick up products from conveniently-located distribution sites, which significantly reduces the number of delivery stops for the food hub's delivery vehicles [129]. The Iowa Food Cooperative, a food hub in central Iowa, follows a similar distribution model, in which customers pick up products from one of seven distribution sites. Similarly, Fifth Season Cooperative, a regional food cooperative in Viroqua, Wisconsin, and Common Market, a regional food distributor in Philadelphia, have multiple aggregation points for regional producers $[130,131]$. Having sufficient cold storage and a loading dock at these locations has been critical, as well as quality inspections to ensure that products meet the food hubs' standards. Full Circle, a food hub in Washington, divided its delivery area into three regions and supplies its customers with products from farmers located within the customers' region [132]. New North Florida Cooperative in Marianna, Florida, cultivated a customer base within a specific geographic region to establish economically-efficient delivery routes [133]. The cooperative also makes efficient use of truck capacity by pairing deliveries to high-volume/low-price customers (e.g., grocery stores) with low-volume/high-price customers (e.g., schools).

The Iowa Food Hub, located in West Union, Iowa, offers hauling services to its producers, in addition to transporting their products to the hub's warehouse [134]. By providing this additional service, the truck is filled with a more complete load and receives additional income from charging hauling fees to producers. Similarly, Potato King, a produce wholesaler and transporter in Wisconsin, maximizes the loads on its trucks by providing a hauling service for regional companies that have 
shipments to be delivered near Potato King's existing customers on its established routes [126]. However, they avoid taking on any extra deliveries that would interfere with their ability to serve their customers.

Some regional food organizations have implemented software for route optimization and load rate maximization. For example, the implementation of a simple vehicle routing tool significantly reduced transportation costs for a regional food delivery company in Mexico [124]. Similarly, the Purchase Area Aquaculture Cooperative implemented a basic program that plans efficient routes, rather than a complex interactive model [127]. Bix Produce, a regional food distributor in Minnesota, uses two different routing systems to create efficient routes [123]. Bix's routing system creates an initial set of fixed routes, and a UPS Logistics Technologies system fine-tunes those routes based on the actual loads and specific stops.

\subsubsection{Backhauling}

Recommended practices-To reduce system transportation costs, RFSC organizations should work together to incorporate backhauling into their distribution routes [37,135]. For example, a food hub could offer a pick-up service for producers along its regular customer delivery route, thereby eliminating delivery trips for the producers and additional pick-ups for the food hub. Similarly, a food hub can partner with a larger regional food distributor by having it pick up products from the food hub during its regular delivery routes [136]. An innovative and efficient distribution model, known as the Farmers' Market Hub, was proposed to increase regional food access for customers in the Greater Los Angeles area [137]. With this model, products from multiple farmers would be aggregated at the farmers' market. Before returning home from the farmers' market, the farmers' empty trucks would be filled with the aggregated product, which would be used to fulfill wholesale orders in their respective regions. Backhauling can also facilitate the use of reusable shipping containers [123]. While this requires up-front investment and additional storage space, regular usage can lead to cost savings and improved environmental sustainability in the long run.

Implemented practices-Although backhauling can reduce RFSC transportation costs, implementation has proved to be challenging, because backhauling increases transportation route complexity and requires additional planning. For example, Bix Produce reported that it often struggles to arrange backhauls [123]. Nevertheless, several regional food organizations have reported successful implementation of backhauling into their distribution routes. Both Cherry Capital Foods, a regional food distributor in Traverse City, Michigan, and La Montanita Co-op in Albuquerque, New Mexico, orchestrate transportation to ensure that whenever possible, all of their trucks backhaul products on their return trips $[138,139]$. This has led to increased transportation efficiency and a reduced carbon footprint. Edina Couriers, a regional distributor in Minnesota, modifies its core routes to backhaul whenever possible, adding freight to avoid empty and less-than-full trucks [123]. Since one major customer defines most of Edina's delivery routes, the routes remain relatively consistent, which reduces the amount of planning and coordination that is necessary for backhauling. Several food hubs in the Hudson Valley have extended their delivery reach by backhauling with distributors and retail stores [56].

\subsubsection{Vehicle Selection}

Recommended practices-For an RFSC organization that provides transportation, choosing the best type of vehicle to meet its needs is essential. If an organization delivers fresh produce, a refrigerated truck that can maintain a consistent temperature is recommended [140]. However, if the organization faces significant financial constraints, a creative vehicle solution may be best. For example, a donated city bus can allow an organization to expand its services and provide a mobile market [18]. Other vehicle options include mobile carts, renovated postal or commissary trucks, and boats. Replacing old vehicles with energy-efficient vehicles can aid in food hub success and sustainability [140]. If a food hub is distributing products nationwide, it might consider utilizing multi-modal freight options to 
reduce costs, increase fuel efficiencies, and avoid traffic congestion [37]. For example, barges could be used for food distribution to cities along the Mississippi River [37]. When purchasing a truck, food hubs are advised to look for vehicles that are common in their area, so that replacement parts can be obtained quickly. This can help a food hub to reduce truck downtime and avoid financial losses due to missed deliveries [134].

Once the appropriate vehicle type has been established, the next decision that an RFSC organization must make is whether to buy or lease a vehicle. To determine whether buying or leasing is more cost-effective, organizations should have a good understanding of all of the relevant costs, including rental costs for a leased vehicle, loan payments for a purchased vehicle, fuel costs, maintenance costs, insurance payments, and taxes [125]. A hybrid strategy, in which some vehicles are purchased and others are leased, can provide flexibility without significant capital investment. For example, a food hub can lease additional vehicles to supplement its purchased fleet during busy seasons [51]. In [134], a detailed overview of the tradeoffs of renting and purchasing a delivery truck has been provided, and the National Good Food Network provides a buy-versus-lease cost comparison tool on its website to assist food hubs in making this decision [141]. Another important decision in vehicle selection is selecting the appropriate vehicle size, based on the maximum load requirements during the peak season. This is an important decision, because fuel efficiency differs significantly for different vehicle sizes. For example, for a semi-trailer, mid-size truck, and pick-up truck, the respective amounts of fuel required to move one ton of product are one, two, and eleven gallons [119]. Vehicles that use alternative fuels are another option; for example, a group of producers can set up a biodiesel operation and reduce their fuel costs significantly [142].

Implemented practices-Several regional food enterprises in the U.S. have retrofitted buses and trucks for cost-effective transportation [143]. Capay Valley Farm Shop in Esparto, California, decided to purchase (rather than lease) its two refrigerated box trucks to avoid lengthy trips to the leasing agency for maintenance [139]. Co-op Partners Warehouse, a regional organic food distributor based in St. Paul, Minnesota, transports products from its warehouse to its customers using one leased truck and six self-owned trucks. The leased truck is used for daily deliveries to its biggest customer, which mitigates risk: The leasing company is obligated to provide a replacement truck if a mechanical problem occurs, so this critical route will always be covered [133]. La Montanita Co-op decided to lease a truck to avoid high upfront purchase costs, and this truck is used to pick up products from many small-scale regional producers and deliver them to multiple stores in Albuquerque and Santa Fe [144]. Organically Grown Company, an organic produce distributor in Eugene, Oregon, has converted its trucks to bio-diesel in an effort to reduce fuel costs [145]. Goodness Greeness, a regional produce distributor in Chicago, Illinois, explored multi-modal options and is now using short line rail to ship carrots instead of a truck [37]. This Old Farm in Colfax, Indiana, has two delivery vehicles: One serves as a primary delivery vehicle, while the other provides flexibility in accommodating emergency and seasonal deliveries [139].

\subsubsection{On-Time and Frequent Deliveries}

Recommended practices-To ensure that customers receive the freshest food possible, it is strongly recommended that RFSC participants make an effort to deliver on time to meet buyers' needs $[4,47,146-148]$. Institutional buyers often prefer to have multiple deliveries each week to avoid stock-outs and to minimize the loss of perishable items [149,150]. Regional Access, a food hub operating in upstate New York, surveyed its customers and found that $33 \%$ of them would increase their purchases if the food hub increased product variety, provided more frequent deliveries, and reduced the time between order placement and delivery [151]. Similarly, survey data from 126 restaurant owners in Iowa indicated that RFSC participants must be highly responsive and offer frequent deliveries to be successful [152].

Implemented practices-Ninety-eight percent of Edina Couriers' deliveries are on time, which allows them to deliver in the small time windows necessary for cross-docking with other distributors [123]. 
Potato King maintains a perfect on-time delivery rate by routing its trucks around adverse weather [126]. Other organizations have focused on providing frequent deliveries. Appalachian Harvest, a local food organization in Abingdon, Virginia, created a single brand to represent all of its producers, which allows them to ship twice per week to a small number of large customers [125]. Co-op Partners Warehouse offers daily deliveries of small volumes, which has attracted restaurants and has helped them differentiate themselves from other organic food distributors in the area [133]. They also deliver on Sundays and offer "short delivery calls" for in-town customers, in which orders received by 10:00 a.m. can be delivered the same day for no extra charge. In an effort to increase sales, Grown Locally, a food hub in northeast Iowa, delivers products twice a week during the growing season [153]. Similarly, Oklahoma Food Cooperative, a regional food cooperative in Oklahoma City, decided to increase the frequency of its deliveries from once to twice per month [133]. However, sales did not increase as expected, because the co-op did not have enough supply to meet the resulting increase in demand. HomeGrown Wisconsin, a marketing cooperative of 25 family farms from southern Wisconsin, regularly updates its product availability list and delivers to restaurants twice a week [144]. Western Montana Growers Cooperative in Arlee, Montana, delivers twice each week in summer and once a week in winter to ensure convenient service for its customers [154].

\subsubsection{Third-Party Logistics (3PL)}

Recommended practices - Contracting with a reasonably priced 3PL provider can be a good way to ensure on-time deliveries [125]. 3PLs can distribute products very efficiently, allowing food hubs to focus on their core competencies [129]. Using a 3PL is highly recommended for food hubs that are in the early stages of their development $[154,155]$. In some cases, 3PL services may be less expensive than in-house distribution; therefore, [37] recommend that food hubs accurately calculate and compare in-house distribution costs with 3PL fees. The authors specifically recommend using regional 3PLs, which are best suited to accommodating the needs of regional food distribution. However, shipper associations, freight forwarders, and common carriers can provide economies of scale for RFSCs, and they can arrange customs clearance [38].

Implemented practices-The use of 3PL providers has varied among different RFSC organizations. Some organizations hire regional 3PLs to help them manage their transportation. Grass Run Farms, a beef producer collective in the Midwest, selected regional distributor Edina Couriers to distribute all of its products to its customers [123,126]. Small food businesses and producers in Central Oregon have contracted with Cascade Couriers, a regional distributor, for pick-up and delivery services [154]. Keewaydin Organics reported cost savings from working with Edina Couriers and Nottestad Trucking, which contracts with Organic Valley (an organic dairy cooperative in Wisconsin) and allows Keewaydin to piggyback on its deliveries [123]. A food store in Ohio uses a regional 3PL to coordinate procurement efforts with small-scale local farmers and to assist with developing efficient pickup and delivery routes [156]. New North Florida Cooperative outsourced its entire order fulfillment operation to a third-party community-based non-profit organization [147]. This organization receives customer orders and coordinates with the farmers to fill and deliver the orders. Ojai Pixie Growers, a food hub in Ojai, California, uses local contractors to haul, organize, and sell their products [157]. Fifth Season Cooperative has partnered with Reinhart Foodservice for transportation, including backhauling the co-op's products from several Wisconsin farms [139]. By setting Fifth Season up as a vendor, Reinhart has also been able to connect the co-op with a pool of potential new customers.

By contrast, some organizations use large-scale national 3PL providers [143]. Good Earth Farms, a producer in Wisconsin, uses a combination of a national parcel service and a regional delivery service for its products [158]. Similarly, This Old Farm contracts with less-than-truckload carriers for non-local sales and works with a regional produce company to arrange backhauling [139]. Farmers in New England contracted with UPS to ship their products to restaurants in New Hampshire, such that farmers can simply drop off products and a chef 200 miles away will receive them the next day. The farmers receive discounts of up to $33 \%$ if enough farmers use the program in a given week [144]. 
High Desert Foods, a small processor of sustainably-grown food located in Durango, Colorado, typically relies on conventional courier services to distribute its products across the U.S. [138]. Organic Valley also uses 3PL providers to distribute products nationwide [159]. Red Tomato, a food hub in Massachusetts, improved operational efficiencies by distributing products via multiple transportation service providers. These providers incorporated their products on existing routes, thereby filling their trucks more completely $[122,131]$.

Other organizations use a 3PL to manage a portion of their deliveries, while distributing the rest themselves. For example, Tuscarora Organic Growers, a cooperative in Pennsylvania, contracts with a trucking company to complete one-third of its deliveries [160]. Often, an organization will deliver to nearby customers and hire a 3PL provider for distant deliveries, thereby increasing its delivery radius. In fact, nearly all of the 11 most successful food hubs in the U.S. use company-owned trucks for local deliveries and outsource long-distance hauling [139]. These relationships help the trucking companies fill partial loads and provide efficient transportation for the food hubs. Full Circle uses two produce distributors to provide long-haul deliveries beyond the reach of their own trucks, which only deliver products locally [132]. Co-op Partners Warehouse makes its own local deliveries and contracts with common carriers to deliver products more than 100 miles away [161].

A 3PL provider can be a practical solution for a regional food organization that is in the early stages of its development, before it develops logistics expertise and is able to invest in distribution infrastructure. For example, a grass-fed beef company in Minneapolis initially used the distribution services of a local food cooperative before gradually developing its own transportation and distribution network [9]. However, the benefits of using a 3PL provider do not always outweigh the costs. The Purchase Area Aquaculture Cooperative originally used a 3PL provider to handle distribution but found that the numerous fees charged by their provider were too expensive [127]. Additionally, using a 3PL resulted in longer delivery times, because the products were routed through a distribution center, rather than being delivered directly to customers. Using a 3PL can also reduce food traceability. In an effort to efficiently provide its customers with regionally-produced food, Sysco, one of the leading food distributors in the U.S., contracted with a 3PL [162]. However, the farmers supplying Sysco were unhappy that their products were commingled with products from other farms, thereby reducing their ability to build their farm's brand.

\subsubsection{Transportation Collaboration}

Recommended practices (Horizontal Collaboration)—Horizontal collaboration among RFSC participants can greatly improve the efficiency of a regional food system and can expand the RFSC's logistics capabilities. For producers in particular, collaboration can be critical to success, allowing them to pool their resources and efforts, rather than trying to do every job on their own [144,163-165]. Collaboration among multiple producers can also help to mitigate their risk through shared benefits and losses [166]. For example, producers can collectively invest in a shared delivery truck $[163,167]$. Collaborative logistics can also provide producers with better access to processing facilities and distribution networks, thereby improving market access for their products $[9,168]$. A study on regional food organizations in Sweden indicated that coordinated transportation has the potential to reduce the number of routes, driving distance, and total transportation time by $68 \%, 50 \%$, and $48 \%$, respectively [39]. A similar study in Bagolino, Italy, demonstrated how small cheese producers could benefit from strategic transportation collaborations [169]. However, implementing traceability systems (e.g., farm-level labeling) would be necessary to enable each product's origins to be identified [4].

While horizontal collaboration can reduce costs for RFSC participants, it can potentially increase their business risk, and it can also slow decision making, since decisions are made by a group rather than individuals [140]. However, the amount of risk incurred depends upon the level of collaboration between the participants. Collaboration is broadly described into three different levels, based on the amount of information exchanged between the collaborating organizations: Cooperating, coordinating, and collaborating networks [170]. As the level of collaboration increases (from cooperating to 
collaborating), participating members become more interdependent, and there is a greater level of investment and reallocation of resources across the network. To reduce risk and increase the likelihood of successful collaboration among regional food organizations, a contract specifying the responsibilities of each involved party is recommended [171] and parameters for membership of the network should be clearly defined [157]. While network members should share information to maintain transparency, they should avoid information sharing that is too frequent or irrelevant.

Recommended practices (Vertical Collaboration)—While the conventional food supply system is largely vertically integrated, vertical collaboration is a relatively new concept in RFSCs [144]. However, collaboration between participants at different echelons of an RFSC can help small producers to survive and compete [8,172], while insufficient vertical coordination can potentially lead to inefficiencies and mistrust. For example, the careless handling of products by other RFSC members can be frustrating for producers, creating concerns about end customers' perceptions of their brand [173]. By contrast, building strategic partnerships with upstream and downstream RFSC members can greatly benefit food hubs and producers $[74,123,156]$. For example, vertical collaboration can facilitate drop shipping, wherein food hubs deliver producers' products directly to customers for a fee. Drop-shipping programs benefit both the food hub, which receives extra revenue, and the producer, which is able to reach wider markets while maintaining its relationships with customers [138].

Additionally, information sharing throughout the RFSC, in conjunction with joint problem solving, can enable increased efficiency and adaptability. However, encouraging information sharing can be challenging, due to the competitive nature of the relationships between supply chain members [173]. Successful implementation of vertical collaboration in RFSCs requires that participants treat each other as partners and engage in regular and effective communication. Regular meetings to evaluate and discuss supply chain performance can help resolve difficulties and bottlenecks in the supply chain [174]. These meetings also allow regional food organizations to assess whether their core business principles are being upheld throughout the supply chain.

Implemented practices (Horizontal Collaboration)—Many regional food producers have reported that they have benefited from horizontal transportation collaboration. Driftless Organics, a farm in Wisconsin, shares distribution efforts with nearby producers and holds regular meetings to share ideas about ways to further increase efficiency [123]. The producers of Grass Run Farms combine their deliveries to increase efficiency, as well as sharing their production, marketing, and administrative expertise with the entire group [123]. By sharing trucking with another company for their long hauls, Eden Natural, a pork producer in Iowa, saved $\$ 0.08$ per mile in transportation costs, an annual savings of over \$25,000 [175]. Good Natured Family Farms, an alliance of local farmers in Kansas, collaborated to combine deliveries to the Balls Food Stores warehouse and share transportation costs [176]. Regional food producers in western France became more economically and environmentally efficient once they began coordinating transportation with one another [177]. New North Florida Cooperative developed multiple autonomous farmer distribution networks to help their farmers to collaborate with one another [133].

Food hubs have also benefited from horizontal transportation collaboration. Southeast Minnesota Food Hub Network, which consists of over 90 producers, collaborates with Co-op Partners Warehouse in St. Paul, Minnesota, to distribute to locations outside the 90-mile range from their main distribution point [130].

Implemented practices (Vertical Collaboration)—Vertical transportation collaboration between food hubs and upstream supply chain members (i.e., producers) has yielded benefits for both parties. For example, Organic Valley wanted to deliver its milk to restaurants, institutions, and grocery stores throughout New Mexico. However, these customers are located outside major U.S. freight routes. To address this challenge, Organic Valley entered into a partnership with La Montanita Co-op in which La Montanita delivers Organic Valley's weekly milk orders to buyers across the state. This partnership helped La Montanita to develop statewide routes for its delivery business and also led to better truck 
utilization [131]. Similar partnerships with other producers have helped them to develop a strong statewide distribution system for regionally-produced food.

Vertical transportation collaboration can also occur downstream in an RFSC, between a food hub and regional food buyers. Co-op Partners Warehouse developed a drop-shipping program for small producers, allowing them to sell their products directly to customers but have Co-op Partners Warehouse make the deliveries [161]. Co-op Partners Warehouse fits the drop-ship deliveries into its regular delivery schedule and bills the producer for the service. Farmigo, an online farmers' market, in Palo Alto, California, connects customers with producers to arrange drop shipping at convenient locations, such as workplaces or churches [18]. La Montanita Co-op maintains a vertically integrated RFSC by holding team meetings with its retail store staff and its distribution center to determine which products should be routed through the distribution center and which should be marketed directly through the retail store [133]. The distribution center also coordinates with producers to directly deliver their products to their customers under their own invoice for a fee.

\subsection{Warehousing}

This sub-section describes recommendations for the five warehousing best practices by RFSC researchers, as well as implementation examples of these practices by RFSC practitioners.

\subsubsection{Effective Labor Utilization}

Recommended practices-Maintaining a professional and skilled workforce is critical to running a successful food hub operation $[133,155,157]$. Effective labor management, including employee training, workload balancing, and appropriate staffing, can help to reduce turnover [17]. Because most regional food hubs in the U.S. employ part-time and/or volunteer workers [139], their labor management strategies must account for the inherent variability of volunteer labor [178]. While the use of volunteer labor reduces operational costs, it can be problematic for efficiency and consistency due to frequent staff turnover [51,139]. In particular, sustaining consistent volunteer labor over long periods of time can be difficult, particularly as their initial enthusiasm diminishes. Additionally, volunteers may lack the necessary skills and experience to take on leadership roles and longer-term responsibilities, which can inhibit a food hub's development $[129,139]$. Food hub managers should systematically track volunteer activities, such that they can identify who performed certain tasks at particular points in time [178]. This will help managers to plan for future staffing needs as the business grows. Also, it is important to develop training materials which can help in faster and efficient on-boarding of new employees [139]. In particular, training employees to load delivery vehicles properly (e.g., loading the last delivery first) is important for regional food distribution efficiency [125].

If a food hub pays its employees, labor efficiency is critical to its financial sustainability. Tracking labor costs and efficiency with appropriate metrics (e.g., sales per worker equivalent) will enable a food hub manager to make informed decisions with respect to labor management [178]. In general, research indicates that high-performing hubs pay their employees more. The performance benefits that are derived from a motivated and loyal workforce tend to outweigh the costs [178].

Implemented practices-To improve labor efficiency, Oklahoma Food Cooperative has made efforts to streamline its sorting processes [133]. Its members built an efficient storage system with dedicated locations for refrigerated, frozen, and nonperishable food items. This system has increased order-processing efficiency, such that the number of volunteer workers has remained steady even as throughput has increased. Other food hubs have discovered that personnel attributes and work culture significantly impact labor efficiency. Much of the success of La Montanita Food Co-op can be attributed to recruiting the right combination of skilled and experienced warehouse staff [133]. Their staff members have extensive backgrounds in warehousing, delivery, management, and operations. The farmers who are members of the Appalachian Harvest network are trained in efficient and effective post-harvest handling methods, including washing, grading, picking, and packing [125]. By contrast, one of the greatest challenges faced by Co-op Partners Warehouse, a Minnesota-based distributor of 
organic products, has been a lack of experienced staff. Their management also suspect that a lack of professionalism in the warehouse's work culture has contributed to lost business opportunities [133]. Greenmarket Co., New York, a wholesale food hub, employed a mix of permanent and seasonal staff to avoid giving volunteers responsibility for key operations [139]. The food hub believes that their employees' institutional knowledge is important for its growth and success.

\subsubsection{Facility Location}

Recommended practices - To minimize transportation time, expense, and emissions, regional food aggregation facilities should be located near major transportation routes and as close to customer bases and growers as possible, particularly when handling perishable goods [53,119,155,157,179]. The decision to locate a facility in a rural or more populous area depends on whether the facility serves primarily growers or urban customers. Locating distribution hubs far from main thoroughfares may serve the immediate aggregation needs of a cluster of producers, but such hubs will struggle to tap into external freight transport systems and leverage existing transportation infrastructure [123]. A strong customer base can also justify selecting an aggregation site that is further from producers [154]. A survey of food hubs across the U.S. reported that food hubs that were not located near a metropolitan area had higher-than-average dependence on grant funding [17].

While proximity to demand is important, there are other factors to consider when selecting facility location, including the availability of a large pool of people with the necessary skills for employment [175]. Food hubs should also co-locate with existing food markets so that each can benefit from the other's existence [180]. For example, a feasibility study conducted in London recommended that food hubs work closely with existing infrastructures, particularly the wholesale markets that already serve much of the city [180]. A facility may have special requirements that can also impact the choice of location. For example, processing facilities require large quantities of water for their operations, so a location that provides access to an abundant supply of water is crucial.

Another factor that may influence a regional food facility location decision is the presence of underserved areas [157]. Food Desert Map created by United States Department of Agriculture shows areas that lack access to fresh and healthy food, based on proximity and accessibility to full-service retail grocery stores [181]. Investors that are interested in developing regional food distribution systems can use the map to determine where to focus sales to improve consumers' access to fresh food. The Wallace Center is also adding food hub locations to an existing online map of regions in the United States that have low access to supermarkets [181].

To assist in facility location decisions, a mathematical model has been developed that can determine the optimal locations for food hubs in the U.S. The model's overall objective is to minimize transportation costs, subject to upper bounds on allowable transport distances and food hub capital costs/capacity, as well as road conditions [182].

Implemented practices-The Virginia Department of Agriculture and Consumer Services determined the locations of four new packing houses based on input from different regional stakeholder groups, including farmers [140]. Proximity to major markets has been an important driver for the success of Smucker's Meat, a small-scale regional meat processing facility in Mount Joy, Pennsylvania [46].

\subsubsection{Infrastructure Development}

Recommended practices-The foundation of an RFSC is the aggregation and distribution infrastructure it has available to move products from farms to markets, in the form required by buyers $[125,183]$. Thus, the development of sufficient infrastructure capacity is necessary to make RFSCs a vital complement to the global food system $[4,45,154]$. However, an organization's level of investment in infrastructure should match its stage of development and its marketing capacities [133] — a food hub should use its storage space and material handling equipment efficiently and not invest in capacity that it does not have plans to use [181]. Relatively small investments in 
infrastructure, such as establishing new or improved loading docks, can offer substantial benefits to regional food producers and distributors [143]. Other recommended infrastructure includes pallet lifters, forklifts, and banding and wrapping equipment, all of which can reduce labor costs and speed up operations at loading docks [184]. The size of a food hub's warehouse should be based on projected peak season weekly pounds sold [119]. To determine this value, a food hub should frequently monitor its space and equipment usage (e.g., the proportion of space occupied in cold storage each week). Alternatively, warehouse size can be based on the farm acreage that supplies it (e.g., five square feet per acre), while allowing for future growth and expansion $[148,179]$.

A food hub might also consider investing in infrastructure that would enable it to provide some basic food processing capabilities (i.e., sorting, trimming, and washing fresh produce) $[119,167]$. If funding for acquiring a new facility is unavailable, alternatives (e.g., repurposing existing facilities such as that of a food bank) should be examined [143,185]. Paying for access to existing supply chain infrastructure or leasing options can also eliminate up-front investment costs $[139,155,186,187]$. A handbook has been published to help RFSC participants find channels for addressing capital and resource challenges [188].

Implemented practices-Some food hubs have reported making significant investments in infrastructure and capacity, often in response to projected or actual demand increases. To accommodate increased sales and anticipated future growth, Co-op Partners Warehouse significantly expanded its warehouse and trucking capacity [133]. This investment strategy has helped them become one of the biggest distributors of organic products in the upper Midwest. In some cases, however, innovative solutions can reduce the need for investment. For example, a local food distributor in Vermont had its producers dip their eggplants in ice water before loading them on the truck to the warehouse to reduce spoilage [150]. Adopting this strategy eliminated the need for investing in a refrigerated truck.

\subsubsection{Efficient Warehousing Policies}

Recommended practices - Standardized methods for product storage, picking, and packaging are critical to the success of regional food hubs [164]. The use of consistent and high-quality packaging methods is particularly important to food buyers [54,140,147,155,183,184,189-192]. A survey of local food retailers in Michigan found that inconsistent product labeling and packaging by regional producers was a major reason for decreased regional food sales [54]. Therefore, buyers typically require standardized packaging materials and consistent sizing and grading methods [156]. In particular, restaurants are accustomed to working with large-scale food distributors that use standardized packaging, which is designed for shipping and handling, refrigeration, extended shelf life, and user-friendliness [163]. Therefore, regional food hubs must work with producers to ensure that packed products meet all buyer requirements [45]. In particular, they should select appropriate containers that do not break down when exposed to water, allow for ventilation, and fit in customer storage facilities and displays. A food hub may also need to repack items from small-scale producers to reach a customer's desired order size [4].

Efforts should also be made to reduce packaging and to use recyclable packaging materials [120]. A study comparing cardboard boxes and reusable plastic containers concluded that cardboard is a better packaging option (both economically and environmentally) for short food supply chains [193]. On the contrary, a similar study conducted in Emilia-Romagna, Italy, concluded that reusable plastic containers will reduce environmental impact [194]. However, increased transportation and labor handling costs associated with reusable containers could result in overall product cost increases.

Implemented practices-Many regional food hubs and producers have made efforts to standardize their packaging methods. The owners of JenEhr Family Farm in Wisconsin visited the kitchens of area restaurants to gain a better understanding of the chefs' preferences, which helped them to improve their picking and packaging policies [146]. Similarly, a group of farmers in Ohio gained insights from a personnel at a regional grocery chain to learn about customers' packaging requirements [156]. Members of HomeGrown Wisconsin standardized their packaging and delivery methods to meet 
the needs of their restaurant customers [144]. An aggregator for small farmers in northern Virginia packs products differently for different customers: Products for retailers are packed in cases, whereas products for processors are packed in bulk [179].

Balls Food Stores provides packing supplies at cost to their regional food suppliers and educates them on how to appropriately pack and deliver products [131,176]. Winter Harvest, an online regional food buying club based in Philadelphia, sends all of the shipping labels for each delivery date and site to participating farmers at the beginning of the growing season [195]. They also assemble individual orders at each delivery site, rather than at the time of picking or at the beginning of a delivery route, which has helped them reduce delivery errors. An organic potato packing plant in Minnesota provides custom packaging by implementing sorting and packing technologies that are used in conventional food supply chains [38]. An automated screen sizer is used to remove small potatoes, and an expanding roll sizer sorts out larger sizes to meet consumer needs. Similarly, Coop Partners Warehouse offers custom-sized packs that are smaller than cases to satisfy the requirements of their restaurant clients [133]. Sysco has successfully incorporated apples grown by small and midsize farms near Grand Rapids, Michigan, into its mainstream supply chain [162]. They customized volumes and pack sizes to meet customer requirements, which led to increased sales to convenience stores and hotels.

Some regional food distributors have made efforts to develop environmentally sustainable packaging systems. For example, Organically Grown Company uses reusable plastic bins instead of waxed boxes [145]. Good Earth Farms is working with FedEx to develop a box with insulating foam that can be returned and recycled [158]. Packaging at Red Tomato uses sustainable materials and is designed to feature local farms' growing practices and to protect perishable products $[131,132,196]$.

\subsubsection{Warehousing Collaboration and Resource Sharing}

Recommended practices (Horizontal Collaboration)—Collaborative warehousing activities can reduce RFSC costs and improve distribution efficiency [197]. For example, producers can purchase packaging materials as a group [163]. Producers can also share storage facilities to reduce warehousing costs in the post-harvest season $[148,167,198]$. Retailers and food hubs often prefer to pick up products at common aggregation points to address the challenge of managing too many vendors [156]. Therefore, multiple producers selling to the same food hub or retailer should consider forming collective aggregation points at one of their farms, which can enable a more consistent volume and frequency of supply, require fewer transactions for the retailer/food hub, and reduce transportation costs $[4,9,51,147,154,156,199,200]$.

Food hubs should also consider collaborative warehousing; new food hubs in particular can benefit from partnering with existing distributors or organizations $[18,56]$. For example, a food hub can lease warehouse space to other organizations to generate additional revenue $[51,129,140]$. Collaboration between food hubs can facilitate inter-hub brokerage and increase each hub's access to infrastructure and technical assistance [157]. In [201], an overview has been provided on how the capacities of regional food hubs can be increased by partnering with other food hubs in proximity. The report also provides information on important attributes that food hub stakeholders should consider before establishing a food hub collaborative network.

Recommended practices (Vertical Collaboration) - Cross-dock consolidation centers allow small-scale farmers to aggregate their products without incurring the high capital and operational costs of a full-service food hub [202]. Cross-docking can also help full-service food hubs improve their logistics operations without requiring additional capital investment $[136,148]$. For example, an analysis of the distribution network of a food hub in North Carolina determined that expanding its service to an additional grocery store would require collaborative cross-docking with the grocery's regional distribution center [136]. A feasibility study for the development of a network of food hubs in California recommended that the food hubs pay to use the existing distribution infrastructure and cross-docking services of food banks [157]. 
Implemented practices (Horizontal Collaboration) - In a survey of 143 food hubs in the U.S., more than half (52\%) reported that they were engaged in either a formal or an informal collaboration, and several had increased their revenues by renting space to other businesses in their region [44]. Some food hubs share extra space in their warehouses with other regional food organizations to bring in additional revenue. For example, Co-op Partner's Warehouse leases space to Featherstone Farm and Equal Exchange when the space is not needed for its own operations [133,161]. Local Food Hub in Charlottesville, Virginia, serves as an aggregating hub for many specialty food distributors in the region [52]. Working with the Local Food Hub has helped Keany Produce, a regional produce distributor in Landover, Maryland, source a greater volume of locally grown produce for its customers than how much it could otherwise have managed independently.

Implemented practices (Vertical Collaboration) - Some farms and food hubs have reported successfully incorporating cross-docking into their operations. For example, Full Circle has developed several small cross-docking facilities in Idaho and eastern Washington to facilitate local deliveries [132]. Others have partnered with larger distributors. Good Natured Family Farms, integrated cross-docking into its distribution network by leveraging the distribution infrastructure of a large grocery chain [174]. Farmers' products are delivered to the grocery's central warehouse, where they are aggregated by Good Natured Family Farms personnel and then distributed to retail stores via the grocery's trucks.

\subsection{Inventory Management}

This sub-section describes recommendations for the five inventory management best practices by RFSC researchers, as well as implementation examples of these practices by RFSC practitioners.

\subsubsection{Warehouse Inventory Management Systems}

Recommended practices-Implementing systematic inventory management procedures will significantly increase the likelihood of a food hub's success. In particular, the use of inventory management technology can increase the speed of information exchange and therefore enhance RFSC efficiency [174]. A good inventory management system will keep track of which products are in stock, on order, and on backorder, and which products have been sold to customers [181]. It will also support the use of first-in-first-out inventory control to ensure that products are sold within their shelf life. If an organization manages a large number of SKUs or has a retail location, it may be necessary to implement a system that supports barcode labeling and scanning [51].

An inventory management system can also serve as an interface that facilitates ordering and information sharing with buyers [156]. For example, Local Dirt (localdirt.com) provides a software platform that allows buyers to quickly and easily assess product availability and order items that are currently in stock, although its usefulness relies on prompt and accurate inventory updates [119]. Alternatively, Local Orbit provides food hubs with all the necessary software tools required to run their business along with customized sales portals, marketing support, and payment processing services [52]. If both producers and distributors/retailers implement inventory management systems and EDI, they can co-manage their inventory through continuous surveillance of electronic purchases, which is a common practice in conventional food supply chains. Implementing inventory management systems will also help producers better manage their record keeping and improve their overall farm management [203]. Ideally, a food hub's inventory management system should also be able to share inventory information with other nearby aggregators that can extend its distribution services beyond its current distribution radius [121].

Food hubs can use either an Excel-based inventory management system, which is highly dependent on manual data entry, or an enterprise resource planning (ERP) system, which automates data exchange as transactions are performed [204]. While inventory management software can be very useful for RFSCs, the price of the software can be prohibitive [123]. Open-source software would eliminate this cost barrier, but a lack of quality and reliable support could be problematic. If a food hub decides to develop its own proprietary inventory management software, this software should 
be customized using inputs from stakeholders who are familiar with the food hub's operations [139]. An overview of software solutions for RFSC inventory management has been provided in [204].

Implemented practices-Some food hubs have reported successfully implementing warehouse inventory management systems. Ecker's Apple Farm in Wisconsin currently records its inventory transactions on paper and transfers this data to QuickBooks, with an eventual goal of adopting inventory management software and eliminating manual record keeping [126]. Bix Produce currently uses an inventory management system that requires manual data entry for order picking but plans to upgrade this system to include electronic scanning [123]. A regional food business in Iowa invested $\$ 1$ million to develop the sophisticated tracking and inventory systems required to work with Sysco [205]. Sysco has worked with the Wallace Center to develop new ordering codes and an inventory management system to support regional food distribution in Grand Rapids, Kansas City, and Chicago [162]. Capay Valley Farm Shop uses a combination of CSAware software, Excel, Google Documents, and QuickBooks for order management and internal tracking [139]. This Old Farm uses custom-designed software to manage traceability, bar-coding, labeling, and order fulfillment [139]. Greenmarket Farmers Markets in New York used QuickBooks to manage orders and inventory in the initial phase of the business's development but then switched to software designed by Food Connex [139]. Oklahoma Food Cooperative uses Local Food Cooperative Software, an open source platform. Though the software make some assumptions on the operational structure of a food hub like weekly delivery cycle, it acts as a cost-effective option for the food hub, especially in their starting phase [52].

\subsubsection{Inventory Tracking and Food Traceability}

Recommended practices - The ability to track inventory as it moves throughout an RFSC is very useful (and often necessary) for producers, distributors, and retailers [9,142,183,197,206]. In particular, the ability to identify which product (i.e., crop type, originating farm, harvest date) was ordered by which customer on what day is essential to successfully manage recalls [204]. Additionally, many consumers want to know the story of the farmers whose products they are buying, including geographic information, and processing methods $[47,150,152,167,174,190-192,207-210]$. Providing this story can add to regional products' perceived value, such that customers are sometimes willing to pay more [211]. Some consumers also want precise information on production methods, agrochemical treatments, frame-size and breed of animals (for meat products), transport and storage methods, the number of hands through which the products have passed from farm to fork, and harvest dates of the products they are buying $[157,203,212,213]$. Therefore, it is important for RFSCs to implement inventory tracking systems that will help them to build customer trust and comply with legal traceability requirements $[173,214]$. Producers and intermediaries that share this information with their customers via labels and packaging make their products more competitive in the market $[154,168,185]$. However, the cost and inconvenience associated with implementing inventory tracking systems may require that producers be incentivized to participate, such as being awarded with long-term contracts [215].

Regional food organizations can use software to track a bill of lading, accept delivery confirmation, and support food recalls [121]. Inexpensive applications developed using tools like MS Office can also be used to improve traceability [215]. Accounting software can provide both inventory tracking and accounting functions in the same system. For example, The Leopold Center for Sustainable Agriculture published a how-to guide with step-by-step instructions for tracking inventory using QuickBooks [216]. For organizations that process food products, the software system should also be able to track lot numbers throughout the production line and the supply chain [181]. To meet food safety requirements, temperature tracking on the production line is also very important for food processors [204]. Temperature tracking is also often required in cold chains [140].

To expedite the inventory tracking process, regional food organizations can replace manual methods with an electronic bar coding system, or an RFID system if selling to wholesale customers [126]. Although RFID tags are more expensive than printed barcode labels, RFID is more efficient, because 
the tags do not need to be visible to be scanned, and multiple items can be scanned at once. Labels with QR codes allow consumers with smartphones to access product and traceability information to learn about the farm or region where the product originated [126]. However, producers can provide this information to their customers without scanning technology by adding information about their products on signage, cases, and PLU codes [155].

Implemented practices-Systems that enable inventory tracking and food traceability have proved to be beneficial to RFSCs. Grass Run Farms and Edina Couriers have both implemented electronic scanning and software systems to track the movement of their products and to provide other supply chain members with accurate inventory data [123]. However, Grass Run Farms found that consumers did not value QR codes enough to justify the cost of implementation [126]. Cherry Capital Foods has ensured food safety by implementing traceability systems throughout their supply chain [131]. Organic Valley implemented its own inventory tracking system that has the ability to trace and recall every case of products [159]. Similarly, every item sold by All Natural Beef Cooperative and Niman Ranch can be traced back to its source [47,128]. FarmLogix, a Chicago-based technology platform, and Fifth Season Cooperative worked together to develop an inventory tracking system that would provide product origin information to consumers [217]. An Irish organic meat brand provided their customers with an access code that can be entered on the distributor's website to access the location of the source farm and how the livestock was raised [218].

Food hubs that aggregate and commingle products from multiple producers are typically unable to identify the specific source of each item they distribute. However, they may still be able to offer some degree of traceability. Red Tomato maintains product traceability by allowing apples from only one producer in each tote, along with the name and description of the farm [133]. By contrast, Bix Produce knows from which two or three farms each product originated and provides customers with information on all of these farms to consumers, thereby maintaining farm identity but avoiding overburdening their operations [123]. Appalachian Harvest addressed this issue by building a single brand that represents all of their farmers and farming methods, rather than maintaining individual farmer identities [125].

\subsubsection{Demand Forecasting}

Recommended practices-Matching regional food supply with demand is a major challenge $[17,148]$. In fact, it is the most cited challenge for food hub growth, based on responses to two U.S. food hub surveys $[17,44]$. Therefore, it is recommended that all RFSC participants have a detailed understanding of supply and demand across their region [121,167]. If producers, aggregators, and buyers are all able to monitor the RFSC's production capacity, quantities purchased, and any unmet demand, they can improve future planning efforts and potentially increase productivity over time. This allows producers to plan their production accordingly and lower their business risk [185]. Therefore, food hub managers should conduct pre-season crop planning with both buyers and producers to more consistently match supply and demand throughout the season $[119,155,190]$. Ideally, food hub managers should have a core group of dedicated producers that participate in crop planning, as well as relationships with a broader range of producers to help fill in any gaps caused by unplanned events [154]. Additionally, setting up informal intent-to-buy agreements with buyers will yield standing orders that make demand patterns more predictable [219].

Market research can provide food hubs with useful demand information and assist them in choosing which products to procure [143]. The granularity of this information varies, from rough overall demand estimates to information on specific customer demand. For example, New Venture Advisors provides a free tool called Local Food MarketSizer, which assists regional food organizations in determining the demand for local food in a particular metropolitan area or state [181]. This tool is unable to provide demand information for specific products, but it can roughly estimate the demand for a class of products (e.g., fruits and vegetables). Alternatively, food hubs and other regional food organizations can go directly to their customers to gather demand information. This can be 
accomplished through online surveys, tracking ordering habits, and speaking with customers about their needs [143].

Implemented practices-Many producers simply track their sales and watch for demand trends for each product that they sell, and they use this information to help plan for the following season [220]. Some food hubs work with buyers to determine their needs and forecast demand. For example, Common Market developed strong customer relationships with several school districts and hospitals that provide them with data on the volumes and types of products demanded by consumers [221]. Oklahoma Food Cooperative also surveys its customers to determine their preferences and then shares the survey results with their producers to support crop planning [133].

Other organizations work closely with producers to manage supply. Balls Food Stores works with the local farmers to have them grow new crop varieties based on customer demand [176]. Alba Organics, a food hub in Salinas, California, develops a crop plan with its producers based on historic sales volumes. This plan is updated periodically as new crops are added and removed, based on customers' requests and producers' constraints, respectively [157]. However, information management has been a challenge for them-the available software in the market is either too sophisticated or costly, or not sophisticated enough. Tuscarora Organic Growers coordinates crop planning with all its farmers to meet weekly market demand based on a historical database for each produce item sold [52]. At HomeGrown Wisconsin, each grower has a pre-season meeting with the co-op manager to review production and sales data from the previous season and examine projected sales for the coming season. While this meeting helps producers with production planning, there is no sales contract between the co-op and its members [144]. Country Natural Beef begins communicating demand requirements to producers 18 months before cattle are needed on farms to ensure that demand is met for special events and holidays [222]. Southeast Minnesota Food Hub Network works with buyers and producers before the growing season to ensure that there is sufficient supply [130]. Organically Grown Company practices extensive production planning with its producers, working with them to create crop plans and production estimates [223]. Appalachian Harvest found that allocating 10-20\% more supply than expected demand was a good strategy, since some producers do not meet their production projections [125].

Some organizations have begun using software to facilitate more accurate and efficient demand management. Keewaydin Farms is developing software to manage its inventory, match supply with demand, and approximate the volumes that each of its producers is able to sell [123]. Local Harvest Supply, a local food distributor in Iowa, also uses software to analyze customer purchasing patterns in an effort to balance supply and demand [123].

\subsubsection{Improved Supplier Reliability}

Recommended practices-Improving supplier reliability can significantly reduce a food hub's exposure to risk, since delivering products in desired quantities at the promised times is critical for maintaining customers $[54,146,154]$. However, this can be a challenge when the food hub and the producers have different objectives. Producers may prefer to primarily sell directly to customers and only sell surplus products to the food hub, whereas food hubs prefer a consistent supply $[173,224,225]$. To maintain a consistent supply of products for their customers, food hubs should work with producers to determine how much they are able to supply and how frequently, and they should consider offering producers incentives to increase consistency and loyalty [51]. Establishing long-term relationships with a few strategic suppliers will ensure consistent pricing, higher quality, and steady product availability [122].

To reduce overall risk, food hubs should buy products from several suppliers, rather than relying on one producer to fulfill their entire demand [226]. This is particularly important for food hubs with wholesale customers, which require consistent deliveries, contract pricing, and volumes [156,174]. To maintain a consistent year-round supply of products for its buyers, food hubs should consider carry both regional and non-regional foods [225]. The food hubs in California have been advised to 
collectively monitor the supply and demand of individual hubs to facilitate sales across member hubs and to reduce problems that arise due to seasonality of their growers [157].

Producers and food hubs can also help to ensure that they have a consistent supply by adding post-harvest management technologies (e.g., food processing and preserving capabilities) to their facilities [47,52,118,120,148,152,167,206,227]. Processing (e.g., freezing, canning, drying) can extend the season for fresh foods, allowing farmers to produce greater volumes during the growing season and then store and sell products year-round without compromising quality [197]. The convenience of processed food is also appealing to many buyers-it is easy to store, ready to use, and less perishable than fresh products $[140,221]$. Thus selling processed food products can help farmers capture better prices [228]. Processing can also increase the utilization of cosmetically imperfect food products [18]. For example, a farmer may be unable to sell imperfect fresh tomatoes, but with the proper equipment and certifications, he/she could process the tomatoes into tomato paste, which can be sold profitably to foodservice customers. Nearly $43 \%$ of surveyed farmers in Minnesota stated that they would be more likely to sell their products through a local food hub that had facilities for processing and value-added activities [119]. However, the up-front costs of purchasing equipment and facilities, as well as daunting certification and licensing requirements, may prevent many growers and food entrepreneurs from producing and selling processed food items [140]. Another possibility is the use of mobile processing units [46]. These may require less up-front investment than a fixed-location unit; however, operating costs may be greater, due to fuel and maintenance.

Implemented practices-Idaho Bounty, a food hub in Idaho, manages risk by using a small group of large-scale producers to fill its wholesale customers' orders [229]. These producers are capable of meeting the quality and quantity requirements of wholesale markets. To maintain consistent availability of regional produce for its customers throughout the year, a local food co-op in Ohio developed relationships with farmers that can supply both fall and spring crops [156]. Similarly, Red Tomato leverages producer networks across the state to extend seasonal availability for its customers [131]. Country Natural Beef has increased the reliability of its supply by paying higher prices to farmers who are willing to breed calves in difficult calving seasons, as well as having farmers breed more cattle in these difficult periods to serve as insurance [222].

Common Market expanded its year-round supply of products by including frozen regional products sourced from its own producers or partner processors [131]. Similarly, Fifth Season Cooperative offers a line of frozen and value-added vegetable blends to extend their season [139]. The co-op also acts as a broker for frozen and refrigerated meat, to avoid inventory holding costs. Originally, each rancher member of the All Natural Beef Cooperative was responsible for producing, processing, and distributing their beef [128]. To reduce its members' costs and increase overall efficiencies, the co-op purchased and renovated an existing processing facility, which has also helped it to maintain a steady supply of beef throughout the year and meet increasing demand [128]. Good Natured Family Farms owns a state-inspected meat processing plant and has found that processing both chicken and beef in the plant maximizes facility and distribution system utilization [230]. They also plan to have the plant become a federally-inspected facility to enable them to distribute their products across state lines [231]. Developing processing facilities has allowed Colorado Homestead Ranches, a distributor of natural beef products raised by family ranches in Gunnison, Colorado, to establish greater economic control of its supply chain and to provide processing capacity to other meat producers in the region [185]. Lorentz Meats in Cannon Falls, Minnesota, is able to efficiently run its processing unit by keeping its three key customers in constant communication with them about scheduling [46]. Anna Marie Seafood in Louisiana developed a cost-effective method of flash freezing shrimp onboard their fishing vessels [232].

\subsubsection{Collaboration and Resource Sharing for Inventory Management}

Recommended practices (Horizontal Collaboration)—RFSC participants are highly interdependent, and "coopetition" - cooperation with competitors—among them is a collective strategy that can expand 
markets and support prices [53,155]. For example, food hubs can reduce their inventory management costs by sharing deliveries, taking advantage of group purchasing, and purchasing pooled insurance policies [139,154,157,174].

Recommended practices (Vertical Collaboration) —Collaboration between upstream and downstream RFSC participants can facilitate frequent just-in-time (JIT) deliveries and inventory reduction. Although holding inventory helps RFSC participants to buffer against supply and demand uncertainties [184], adopting frequent JIT deliveries and systems that support inventory tracking and demand forecasting can reduce the need for excess inventory and large warehouse spaces [51,183]. Food hubs, which have limited cash flows, will benefit from keeping their inventory levels low and ensuring rapid inventory turnover [233]. However, the high level of coordination that is needed to support JIT deliveries requires significant information sharing between RFSC participants, which can be challenging if they are competitors [173].

Implemented practices (Horizontal Collaboration)—Stonyfield Farm, a dairy company in New Hampshire, has benefited from collaborating with Organic Valley to aggregate and process organic fluid milk [159]. Both companies jointly market the milk, and Wisconsin-based Organic Valley benefits from Stonyfield's strong brand presence in the Northeast region. La Montanita Co-op realized that developing a strong regional supply base would require partnering with competitors, such as Whole Foods [133]. Sysco has encouraged its regional operators to share both information and suppliers, thereby extending its geographic radius of regional food distribution [162].

Implemented practices (Vertical Collaboration)-Vertical coordination in RFSCs for inventory management is practiced by successful food hubs in the U.S. through the development of strategic relationships between upstream and downstream participants [20]. For example, Iowa Food Hub was able to reduce its inventory levels by ordering products more frequently from producers [233]. This also allowed the food hub to make more frequent deliveries, which helped their customers to avoid shortages and to reduce their own inventory levels. Capay Valley Farm Shop uses a JIT system to purchase and pick up products from producers and immediately deliver them to their customers [139]. Grass Run Farms manages its inventory using Excel spreadsheets and has been able to reduce its week-to-week inventory to just a few boxes of product [126]. Country Natural Beef participates in a vendor-managed inventory system in which its customers own six warehouses and purchase the products, but Country Natural Beef manages the inventory for them [222].

Vertical information sharing has increased the effectiveness of many RFSC collaborations. For example, Walsma and Lyons and Sysco Grand Rapids, two food distributors in Michigan, regularly visit producers to learn about their operations and to build trust [174]. Over a three-year period of building relationships, they have doubled the amount of regional produce that they distribute, and they have helped producers expand their delivery reach. Sysco maintains a vertically integrated supply chain by establishing a communication channel between Sysco's staff, local aggregators, and farmers, as well as connecting farmers with customers at the beginning of the season [162]. Kansas City retail chain Balls Food Stores has been able to source more regional food by partnering with Good Natured Family Farms [131]. The grocery managers regularly visit the producers to gain a better understanding of their production practices, and the producers visit stores to showcase products and engage customers. This strategic partnership has yielded \$3 million in sales for the cooperative and has helped to maintain consistent supply to the stores, even in slow seasons [128], [174]. Similarly, a large-scale food distributor in Ohio maintains relationships with regional growers by visiting their farms, inspecting their facilities and growing standards, and conducting soil tests [156]. If the producers meet the distributor's required standards, they become an approved supplier; otherwise, they are dropped as a vendor.

\section{Summary of Findings}

This section provides a summary of the works cited, identifies several gaps in the existing research on RFSC logistics management, and recommends directions for future research. This paper 
summarized and analyzed 106 technical reports (published between 2002 and 2015) and 28 journal articles (published between 2007 and 2016) that provided recommendations and/or examples of implementation with respect to logistics best practices in RFSCs. A summary of the references reviewed in Section 5 for each best practice is provided in Table 3. The RFSC implementation examples are make reference to 67 different regional food practitioners (e.g., farms, cooperatives, food hubs).

Table 3. Summary of reviewed literature on RFSC logistics best practices (technical reports; journal articles).

\begin{tabular}{|c|c|c|}
\hline Best Practice & Recommended & Implemented \\
\hline Efficient Vehicle Utilization & [4], [8], [9], [119-123], [125]; [118], [124] & [123], [126-134]; [124] \\
\hline Backhauling & [37], [123], [135-137] & [56], [123], [138], [139] \\
\hline Vehicle Selection & [18], [37], [51], [119], [125], [134], [140-142] & [37], [133], [139], [143-145] \\
\hline On-time and Frequent Deliveries & [4], [47], [146-149]; [150-152] & $\begin{array}{l}\text { [123], [125], [126], [133], [144], } \\
\text { [153], [154] }\end{array}$ \\
\hline Third-party Logistics (3PL) & [37], [38], [125], [129], [154], [155] & $\begin{array}{l}\text { [9], [122], [123], [126], [127], [131], } \\
\text { [132], [138], [139], [143], [144], } \\
\text { [147], [154], [156-162] }\end{array}$ \\
\hline Transportation Collaboration & $\begin{array}{l}\text { Horizontal collaboration-[4], [9], [140], [144], } \\
\text { [157], [163], [164], [166], [167], [170], [171]; } \\
\text { [39], [165], [168], [169] } \\
\text { Vertical collaboration-[8], [123], [138], [144], } \\
\text { [156], [173], [174]; [172] }\end{array}$ & $\begin{array}{l}\text { Horizontal collaboration-[123], } \\
\text { [130], [133], [175], [176]; [177] } \\
\text { Vertical collaboration-[18], [131], } \\
{[133],[161]}\end{array}$ \\
\hline Effective Labor Utilization & $\begin{array}{l}\text { [17], [51], [125], [129], [133], [139], [155], } \\
{[157],[178]}\end{array}$ & [125], [133], [139] \\
\hline Facility Location & $\begin{array}{l}\text { [17], [53], [119], [123], [154], [155], [157], } \\
\text { [175], [179], [180], [181]; [182] }\end{array}$ & [46], [140] \\
\hline Infrastructure Development & $\begin{array}{l}\text { [4], [45], [119], [125], [133], [139], [143], [148], } \\
\text { [154], [155], [167], [179], [181], [184], [188]; } \\
\text { [183], [185-187] }\end{array}$ & [133]; [150] \\
\hline Efficient Warehousing Policies & $\begin{array}{l}\text { [4], [45], [120], [140], [147], [155], [156], [163], } \\
\text { [164], [184], [189-192]; [54], [183], [193], [194] }\end{array}$ & $\begin{array}{l}\text { [38], [131-133], [144-146], [156], } \\
{[158],[162],[176],[179],[195],} \\
{[196]}\end{array}$ \\
\hline $\begin{array}{l}\text { Warehousing Collaboration and } \\
\text { Resource Sharing }\end{array}$ & $\begin{array}{l}\text { Horizontal collaboration-[4], [9], [18], [51], } \\
\text { [56], [129], [140], [147], [148], [154], [156], } \\
\text { [157], [163], [167], [197], [198], [201]; [199], } \\
\text { [200] } \\
\text { Vertical collaboration-[136], [148], [157], [202] }\end{array}$ & $\begin{array}{l}\text { Horizontal collaboration-[44], [52], } \\
\text { [133], [161] } \\
\text { Vertical collaboration-[132], [174] }\end{array}$ \\
\hline $\begin{array}{l}\text { Warehouse Inventory } \\
\text { Management Systems }\end{array}$ & $\begin{array}{l}\text { [51], [52], [119], [121], [123], [139], [156], } \\
\text { [174], [181], [203], [204] }\end{array}$ & [52], [123], [126], [139], [162], [205] \\
\hline $\begin{array}{l}\text { Inventory Tracking and Food } \\
\text { Traceability }\end{array}$ & $\begin{array}{l}\text { [9], [47], [121], [126], [140], [142], [154], [155], } \\
\text { [157], [167], [174], [181], [190-192], [197], } \\
\text { [203], [204], [207-211], [213], [216]; [150], } \\
{[152],[168],[173],[183],[185],[206],[212],} \\
{[214],[215]}\end{array}$ & $\begin{array}{l}\text { [47], [123], [125], [126], [128], [131], } \\
\text { [133], [159], [217], [218] }\end{array}$ \\
\hline Demand Forecasting & $\begin{array}{l}\text { [17], [44], [119], [121], [143], [148], [154], } \\
\text { [155], [167], [181], [190], [219]; [185] }\end{array}$ & $\begin{array}{l}\text { [52], [123], [125], [130], [133], [144], } \\
\text { [157], [176], [220-223] }\end{array}$ \\
\hline Improved Supplier Reliability & $\begin{array}{l}\text { [18], [46], [47], [51], [52], [119], [120], [122], } \\
\text { [140], [146], [148], [154], [156], [157], [167], } \\
{[174],[197],[221],[224],[226],[228] ;[54],} \\
{[118],[152],[173],[206],[225],[227]}\end{array}$ & $\begin{array}{l}\text { [46], [128], [131], [139], [156], [222], } \\
{[229-232] ;[185]}\end{array}$ \\
\hline $\begin{array}{l}\text { Collaboration and Resource } \\
\text { Sharing for Inventory } \\
\text { Management }\end{array}$ & $\begin{array}{l}\text { Horizontal collaboration-[53], [139], [154], } \\
\text { [155], [157], [174] } \\
\text { Vertical collaboration-[51], [184], [233]; [173], } \\
\text { [183] }\end{array}$ & $\begin{array}{l}\text { Horizontal collaboration-[133], } \\
\text { [159], [162] } \\
\text { Vertical collaboration-[20], [126], } \\
{[128],[131],[139],[156],[162],} \\
{[174],[222],[233]}\end{array}$ \\
\hline
\end{tabular}

This substantial literature reflects the growing importance of logistics in regional food system research over the past decade. Figure 3 shows the publication trend of the reviewed literature over 
time, which demonstrates significant growth in the number of publications in this domain from 2006 through 2014. However, there was a significant decrease in publications in 2015. This paper reviewed journal articles that were available online as of February 2016 and technical reports available as of March 2016, which may be the reason for the significant drop in the number of publications published that year.

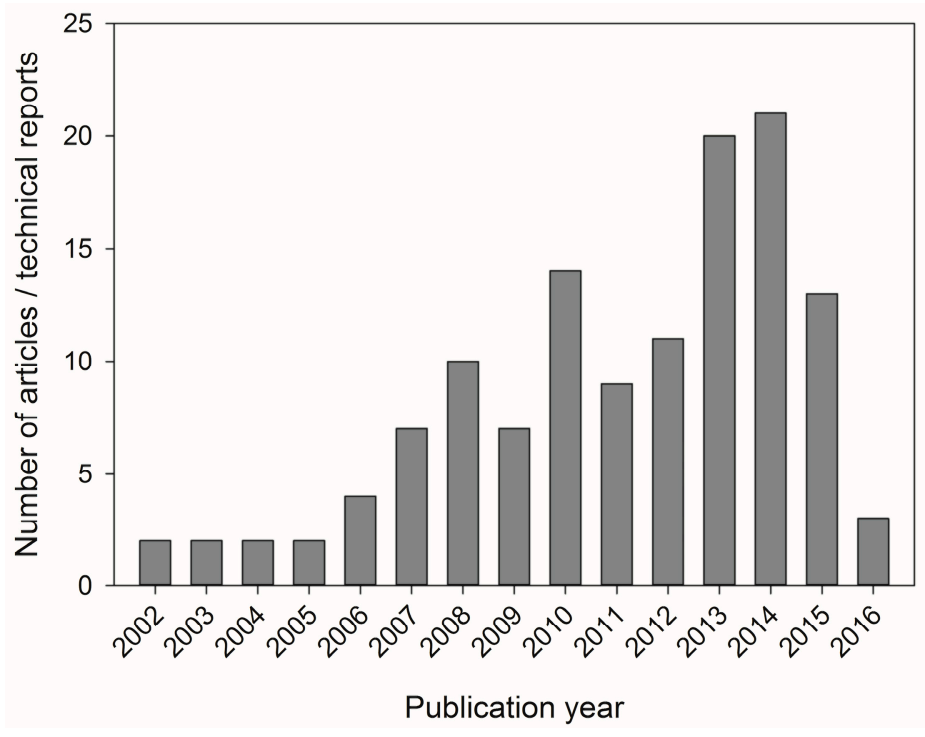

Figure 3. Publication trend of the reviewed literature.

An analysis of this literature indicates that majority of the research on RFSC logistics is being performed in specific geographic areas. Figure 4 shows the geographic dispersion of authors of the literature reviewed in this study. Most of the journal articles on RFSC logistics have been published by researchers in Europe (46\%), and United States (46\%). The remaining $(8 \%)$ articles were from either Mexico or Canada. For shortlisting the technical reports, only research centers in the U.S. were considered. Therefore, reports originated mainly from the U.S., with two reports from the United Kingdom. In the U.S., the research is concentrated on the East Coast, the upper Midwest, and California.

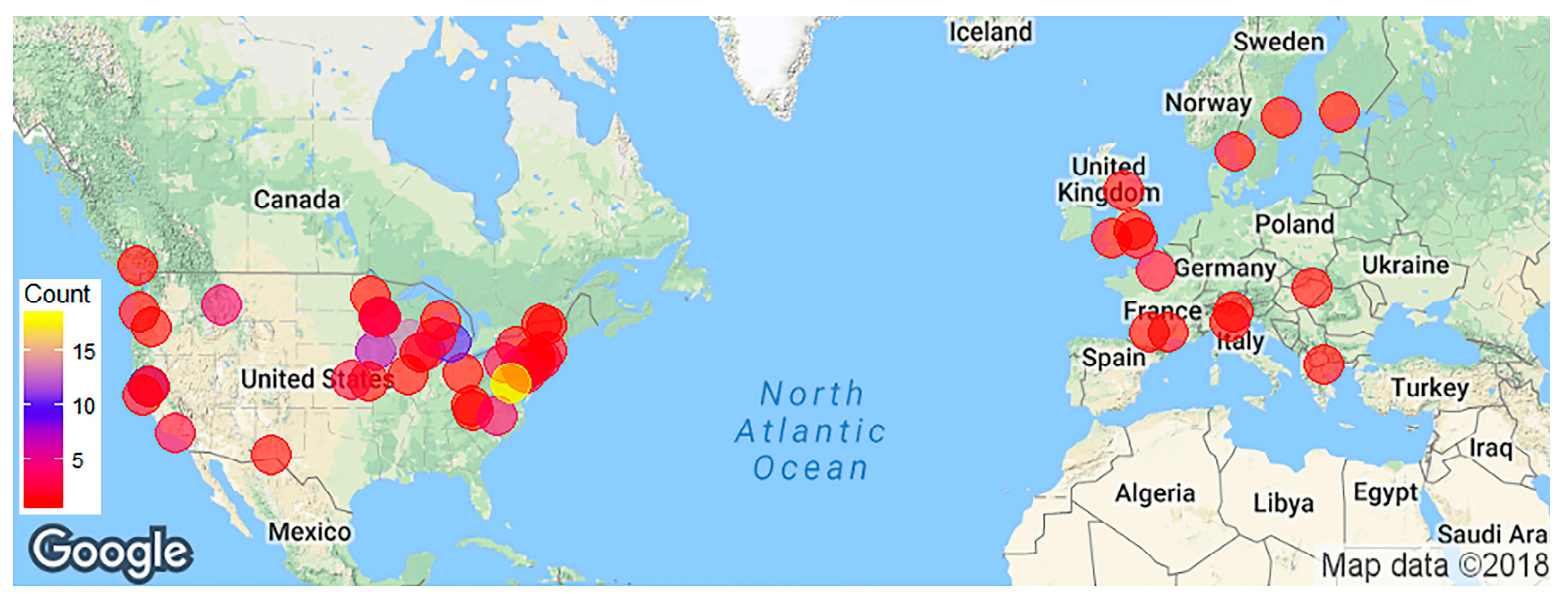

Figure 4. Geographic dispersion of reviewed literature.

In the reviewed literature, the most frequently recommended best practice for RFSCs is inventory tracking and food traceability, with 35 publications mentioning its importance. Having detailed 
information about a food product's origin is very important to most regional food consumers, and an inventory tracking system can help producers, distributors, and retailers to preserve and share this information as the product moves along the RFSC. Moreover, a high degree of traceability helps RFSCs differentiate themselves from the conventional food system, which serves as a competitive advantage.

After inventory tracking and food traceability, the next most frequently recommended best practice for RFSCs is horizontal collaboration, which can be applied to transportation, warehousing, and inventory management (recommended in total by 32 publications). The potential to reduce operational and overhead costs makes horizontal collaboration particularly promising for RFSC participants, who typically lack access to capital. Horizontal collaboration can also facilitate the implementation of other highly-recommended best practices. For example, partnerships among RFSC practitioners can be leveraged to develop new shared infrastructure (recommended in 19 publications), such as food processing and cold storage facilities, and to improve the reliability and off-season supply of regional food (recommended by 28 publications). Such partnerships can also enable the creation of a common vehicle fleet that can support efficient vehicle utilization (recommended by 11 publications), backhauling (recommended by 5 publications), and frequent and on-time deliveries to customers (recommended by 9 publications).

The third most frequently recommended best practice is supplier reliability improvement (recommended by 28 publications). This is unsurprising, given that the irregular supply of products is one of the major reasons for food hub failure and closure in the U.S. [234].

By contrast, the most frequently cited implementation of RFSC logistics best practices was the use of 3PLs (19 examples). Because most RFSC organizations lack the financial capability to invest in infrastructure development, hiring a 3PL to support their logistics operations is a logical choice. The second most frequently cited examples of implementation were from efficient vehicle utilization (16 examples) followed by vertical collaboration (13 examples).

Based on the review of the RFSC logistics literature, three major gaps in the research were identified. These gaps suggest potential avenues for future research to address the biggest logistics challenges faced by RFSC practitioners.

Research Gap \#1: Appropriately tailored implementation of logistics best practices-The regional food community is highly diverse. Regional producers' logistics management requirements vary widely, based on their production capacity, the types of food they are producing, the location of their farm, and seasonal weather conditions at their location. Similarly, regional food distributors and food hubs have unique logistics requirements and capabilities. For example, there are approximately 302 regional food hubs in the U.S., and no two have the exact same business structure. They are characterized by a variety of different capacities, financial models, ownership structures (e.g., non-profits, farmer groups, private entities) and business missions (e.g., maximizing producer profits, providing healthy food to underserved areas, supporting environmentally-friendly agricultural practices). There are also many different food hub operational structures and strategies, including farm-to-school distribution, retail grocery stores, acting as a 3PL provider for regional producers, farm-to-wholesale distribution, as well as hybrid combinations of these structures.

For this reason, it is very difficult to identify from the existing literature which logistics approaches are most appropriate for a specific RFSC entity, and at what level they should be implemented. An examination of best practices at a more targeted level (e.g., by closer examination of food hubs with similar social goals) would greatly help RFSC participants make informed decisions. For example, horizontal collaboration is one of the most widely discussed logistics best practice in the literature. However, none of these publications addressed the need for a framework for successful RFSC collaborations. Such a framework could provide guidance on how to efficiently build and manage the collaboration, how to decide on adding a new member to a preexisting network of collaborating members, how to assign roles and responsibilities to each member (including leadership), and how the benefits of collaboration will be shared among members. There is a large body of literature on collaboration in conventional supply chains [81], some of which focuses on 
small and midsize enterprises in the agri-food industry [235]. However, many RFSC participants are values-based organizations with strong social and environmental components in their business missions [236,237], and the existing profit-focused frameworks on horizontal collaboration may conflict with RFSC objectives [238]. Also, RFSC participants typically face financial constraints that prevent them from adopting sophisticated supply chain technologies that are typically recommended to facilitate horizontal collaboration in conventional supply chains [239]. Therefore, the development of an appropriate framework to provide RFSC practitioners with guidance on how to collaborate that is aligned with their structures and missions is needed.

Research Gap \#2: Economically viable logistics solutions-Infrastructure development (recommended by 19 publications), maintaining a professional and skilled workforce (recommended by 9 publications), making frequent and on-time deliveries (recommended by 9 publications), and deploying traceability tools (recommended by 35 publications) and warehouse inventory management systems (recommended by 11 publications) are highly recommended for RFSCs to help them grow and successfully compete with conventional food supply chains. These best practices will help RFSCs to preserve farm identity throughout the supply chain and make frequent deliveries of fresh food to customers, which are capabilities that differentiate RFSCs from conventional food systems and are necessary to fulfill customers' requirements for product traceability and freshness. However, these best practices require significant financial investment for implementation, which prevents most RFSC participants from adopting them. Many RFSC practitioners are heavily dependent on external funding and grants to survive, particularly in the early stages of their business development. Because of this, technologies for food traceability and inventory management that have been widely adopted by conventional food supply chains are out of reach for RFSCs.

Unfortunately, research on cost-effective strategies for implementing these technology-based best practices in RFSCs is lacking. RFSCs would greatly benefit from the development of innovative and economically viable versions of the tools used by conventional supply chains. For example, a low-cost and low-maintenance inventory tracking system was developed for collaborating food hubs and farmers in Iowa [240]. This system includes an Excel-based label generator interface for the farmers and a mobile application for the food hub managers and truck drivers to track the movement of the farmers' products through the supply network in real time.

Research Gap \#3: Data-driven decision support-Transportation cost has been cited as a major logistical barrier for RFSCs. To overcome this barrier, RFSC participants are advised to use the efficient services of a 3PL provider, or to tap into the existing distribution networks of conventional supply chains to transport products to their customers (recommended by 6 publications). This best practice is the most highly-cited implementation (19 examples). However, decisions about adopting these practices are typically made on an ad-hoc basis, because RFSC practitioners usually have very little background in business planning and supply chain management [44,197].

Therefore, data-driven decision tools based on quantitative evaluations should be developed to help RFSC practitioners make smart logistics management decisions, such as determining the maximum delivery distance for which they should use their own transportation network and the appropriate terms and conditions for a third-party contract. Such decision support tools can help producers decide which costs (i.e., transportation, warehousing, processing) to absorb and which to pass on to their customers [47]. For example, a computer simulation model was developed to enable food hub managers to understand the effects of various scheduling policies on the efficiency of their warehouse operations [241-243].

\section{Conclusions}

This paper presented a structured review of the literature on logistics management in RFSCs. To the best of our knowledge, this is the first organized effort in conducting a systematic literature review on RFSC logistics. This review can serve as a source guide and starting point for RFSC practitioners to gain insights on potential solutions to logistics challenges, which are often the biggest 
barriers to their growth and success. The recommendations and implementation examples for the 16 best practices cited in this paper will also give RFSC practitioners an opportunity to connect with fellow practitioners and RFSC researchers who have experienced similar challenges and have identified workable solutions. Most importantly, this review has identified several gaps in the existing RFSC literature, which opens up potential research avenues and provides research directions for the academic community. As demand for regionally-produced food continues to grow, the knowledge gained from this research will be increasingly necessary to support efficient and effective connections between consumers and producers and overall regional food system success.

Acknowledgments: This work was supported by grant M2015-11 from Leopold Center for Sustainable Agriculture at Iowa State University, Ames, Iowa.

Conflicts of Interest: The authors declare no conflict of interest.

\section{References}

1. U.S. Department of Agriculture. Direct Farm Sales of Food: Results from the 2015 Local Food Marketing Practices Survey; United States Department of Agriculture: Washington, DC, USA, 2016.

2. National Grocers Association and Supermarket Guru. 2015 Consumer Survey Report; National Grocers Association: Arlington, VA, USA; Supermarket Guru: Santa Monica, CA, USA, 2015.

3. Feldmann, C.; Hamm, U. Consumers' Perceptions and Preferences for Local Food: A Review. Food Qual. Preference 2015, 40, 152-164. [CrossRef]

4. Martinez, S.; Hand, M.; Da Pra, M.; Pollack, S.; Ralston, K.; Smith, T.; Vogel, S.; Clark, S.; Lohr, L.; Low, S. Local Food Systems: Concepts, Impacts, and Issues; United States Department of Agriculture: Washington, DC, USA, 2010.

5. Schnell, S.M. Food Miles, Local Eating, and Community Supported Agriculture: Putting Local Food in its Place. Agric. Hum. Values 2013, 30, 615-628. [CrossRef]

6. Hendrickson, M.K.; Heffernan, W.D. Opening Spaces through Relocalization: Locating Potential Resistance in the Weaknesses of the Global Food System. Sociol. Rural 2002, 42, 347-369. [CrossRef]

7. Smithers, J.; Johnson, P. The Dynamics of Family Farming in North Huron County, Ontario. Part I. Development Trajectories. Can. Geogr. 2004, 48, 191-208. [CrossRef]

8. Low, S.A.; Adalja, A.; Beaulieu, E.; Key, N.; Martinez, S.; Melton, A.; Perez, A.; Ralston, K.; Stewart, H.; Suttles, S.; et al. Trends in U.S. Local and Regional Food Systems: Report to Congress; United States Department of Agriculture: Washington, DC, USA, 2015.

9. King, R.P.; Hand, M.S.; DiGiacomo, G.; Clancy, K.; Gómez, M.I.; Hardesty, S.D.; Lev, L.; MCLAUGHLIN, E.W. Comparing the Structure, Size, and Performance of Local and Mainstream Food Supply Chains; United States Department of Agriculture: Washington, DC, USA, 2010.

10. Hardesty, S.D. The Growing Role of Local Food Markets. Am. J. Agric. Econ. 2008, 90, 1289-1295. [CrossRef]

11. Clifford, S. Wal-Mart to Buy More Local Produce; The New York Times: New York, NY, USA, 2010.

12. Ralston, K.; Benson, M. Many U.S. School Districts Serve Local Foods; United States Department of Agriculture: Washington, DC, USA, 2015.

13. Harris, D.; Lott, M.; Lakins, V.; Bowden, B.; Kimmons, J. Farm to Institution: Creating Access to Healthy Local and Regional Foods. Adv. Nutr. Int. Rev. J. 2012, 3, 343-349. [CrossRef] [PubMed]

14. Barham, J. Getting to Scale with Regional Food Hubs. U.S. Department of Agriculture, 2010. Available online: https://www.usda.gov/media/blog/2010/12/14/getting-scale-regional-food-hubs (accessed on 4 November 2017).

15. Jensen, J. Local and Regional Food Systems for Rural Futures; Rural Policy Research Institute: Iowa City, IA, USA, 2010.

16. Foley, K.; Goodman, T.; McElroy, B. Bridging the Gaps: Funding and Social Equity Across the Food System Supply Chain; RSF Social Finance: San Francisco, CA, USA, 2012.

17. Fischer, M.; Hamm, M.; Pirog, R.; Fisk, J.; Farbman, J.; Kiraly, S. Findings of the 2013 National Food Hub Survey; Center for Regional Food Systems, Michigan State University: East Lansing, MI, USA; Wallace Center at Winrock International: Arlington, VA, USA, 2013. 
18. Pansing, C.; Wasserman, A.; Fisk, J.; Muldoon, M.; Kiraly, S.; Benjamin, T. North American Food Sector, Part One: Program Scan E Literature Review; Wallace Center at Winrock International: Arlington, VA, USA, 2013.

19. Lerman, T.; Feenstra, G.; Visher, D. A Practitioner's Guide to Resources and Publications on Food Hubs and Values-Based Supply Chains: A Literature Review; Agricultural Sustainability Institute, University of California, Davis: Davis, CA, USA, 2012.

20. Karnitz, N.; Mao, J.; Mathers, D.; Patnode, S.; Xu, X. Rural Minnesota Food Systems and Food Hub Overview; University of Minnesota Extension: Saint Paul, MN, USA, 2013.

21. Lerman, T. A Review of Scholarly Literature on Values-Based Supply Chains; Agricultural Sustainability Institute, University of California, Davis: Davis, CA, USA, 2012.

22. Lerman, T.; Feenstra, G.; Visher, D. An Annotated Bibliography of Publications and Resources on Food Hubs and Values-Based Supply Chains; Agricultural Sustainability Institute, University of California, Davis: Davis, CA, USA, 2012.

23. Guel, A.; Pirog, R. An Annotated Bibliography on Structural Racism Present in the Food System; Center for Regional Food Systems, Michigan State University: East Lansing, MI, USA, 2017.

24. Ritchie, S.M.; Chen, W.-T. Farm to School: A Selected and Annotated Bibliography; United States Department of Agriculture: Washington, DC, USA, 2011.

25. Kremer, P.; Schreuder, Y. The Feasibility of Regional Food Systems in Metropolitan Areas: An Investigation of Philadelphia's Foodshed. J. Agric. Food Syst. Community Dev. 2012, 2, 171-191. [CrossRef]

26. Mentzer, J.J.T.; Dewitt, W.; Keebler, J.S.; Zacharia, Z.G. Defining Supply Chain Management. J. Bus. Logist. 2001, 22, 1-25. [CrossRef]

27. Ross, D.F. Competing Through Supply Chain Management: Creating Market-Winning Strategies through Supply Chain Partnerships; Springer Science \& Business Media: New York, NY, USA, 1997.

28. Gebresenbet, G.; Bosona, T. Logistics and Supply Chains in Agriculture and Food. In Pathways to Supply Chain Excellence; InTech: London, UK, 2012.

29. Dey, A.; LaGuardia, P.; Srinivasan, M. Building Sustainability in Logistics Operations: A Research Agenda. Manag. Res. Rev. 2011, 34, 1237-1259. [CrossRef]

30. Ballou, R.H. Business Logistics/Supply Chain Management: Planning, Organizing, and Controlling the Supply Chain; Pearson Education India: Kannur, India, 2007.

31. Chopra, S.; Meindl, P. Supply Chain Management. Strategy, Planning E Operation; Pearson Education: Upper Saddle River, NJ, USA, 2007.

32. Lummus, R.R.; Krumwiede, D.W.; Vokurka, R.J. The Relationship of Logistics to Supply Chain Management: Developing a Common Industry Definition. Ind. Manag. Data Syst. 2001, 101, 426-432. [CrossRef]

33. Van der Vorst, J.; Beulens, A.; van Beek, P. Innovations in Logistics and ICT in Food Supply Chain Networks. In Innovation in Agri-Food Systems; Jongen, W.M.F., Meulenberg, M.T.G., Eds.; Wageningen Academic Publishers: Noordwijk, The Netherlands, 2005; pp. 245-292.

34. Aghazadeh, S.M. Improving Logistics Operations Across the Food Industry Supply Chain. Int. J. Contemp. Hosp. Manag. 2004, 16, 263-268. [CrossRef]

35. Ahumada, O.; Villalobos, J.R. Application of Planning Models in the Agri-food Supply Chain: A Review. Eur. J. Oper. Res. 2009, 196, 1-20. [CrossRef]

36. Meixell, M.J.; Norbis, M. A Review of the Transportation Mode Choice and Carrier Selection Literature. Int. J. Logist. Manag. 2008, 19, 183-211. [CrossRef]

37. Day-Farnsworth, L.; Miller, M. Networking Across the Supply Chain: Transportation Innovations in Local and Regional Food Systems; Center for Integrated Agricultural Systems, University of Wisconsin-Madison: Madison, WI, USA, 2014.

38. Vanwechel, T.; Vachal, K.; Berwick, M. The Logistics of Niche Agricultural Marketing; United States Department of Agriculture: Washington, DC, USA, 2007.

39. Bosona, T.G.; Gebresenbet, G. Cluster Building and Logistics Network Integration of Local Food Supply Chain. Biosyst. Eng. 2011, 108, 293-302. [CrossRef]

40. Mundler, P.; Rumpus, L. The Energy Efficiency of Local Food Systems: A Comparison Between Different Modes of Distribution. Food Policy 2012, 37, 609-615. [CrossRef]

41. Gebresenbet, G. Promoting Effective Goods Distribution through Route Optimization and Coordination to Attenuate the Environmental Impact: The Case of Uppsala; Institutionen för Lantbruksteknik, Sveriges Lantbruksuniversitet: Uppsala, Sweden, 1999. 
42. Woods, T.; Velandia, M.; Holcomb, R.; Dunning, R.; Bendfeldt, E. Local Food Systems Markets and Supply Chains. Choices 2013, 28, 1-4.

43. BJH Advisors. Regional Food Hubs Task Force—Final Action Plan; BJH Advisors, LLC: New York City, NY, USA, 2015.

44. Hardy, J.; Hamm, M.; Pirog, R.; Fisk, J.; Farbman, J.; Fischer, M. Findings of the 2015 National Food Hub Survey; Center for Regional Food Systems, Michigan State University: East Lansing, MI, USA; Wallace Center at Winrock International: Arlington, VA, USA, 2016.

45. Cantrell, P. See the Local Difference: Regional Food Systems Become Essential Ingredient for Michigan's Future; Michigan Land Use Institute: Traverse City, MI, USA, 2009.

46. Gwin, L.; Thiboumery, A.; Stillman, R. Local Meat and Poultry Processing: The Importance of Business Commitments for Long-Term Viability; United States Department of Agriculture: Washington, DC, USA, 2013.

47. Conner, D.S.; Hamm, M.W. The Economics of Pasture Raised Animal Products: Food, Markets and Community; Michigan State University: East Lansing, MI, USA, 2007.

48. Clancy, K.; Ruhf, K. Is Local Enough? Some Arguments for Regional Food Systems. Choices Mag. Food Farm Resour. Issue 2010, 25, 1-5.

49. Christie, M. Scaling Up Local Food: Investing in Farm E Food Systems Infrastructure in the Pioneer Valley; Community Involved in Sustaining Agriculture: South Deerfield, MA, USA, 2011.

50. Cheng, M.; Seely, K. Building Regional Produce Supply Chains: Helping Farms Access and Sell to Multiple Channels; FarmsReach: Berkeley, CA, USA, 2012.

51. Matson, J.; Thayer, J.; Shaw, J. Running a Food Hub: A business Operations Guide; United States Department of Agriculture: Washington, DC, USA, 2015.

52. Barham, J.; Tropp, D.; Enterline, K.; Farbman, J.; Fisk, J.; Kiraly, S. Regional Food Hub Resource Guide; United States Department of Agriculture: Washington, DC, USA, 2012.

53. Haddad, H.; Nyquist, K.; Record, L.; Slama, J. Ready to Grow: A Plan for Increasing Illinois Fruit and Vegetable Production; FamilyFarmed: Chicago, IL, USA, 2010.

54. Abatekassa, G.; Peterson, H.C. Market Access for Local Food through the Conventional Food Supply Chain. Int. Food Agribus. Manag. Rev. 2011, 14, 63-82.

55. Schattman, R.; Cannella, M. Maintaining Farm Identity Through Alternative Marketing Practices; Intervale Center: Burlington, VT, USA, 2008.

56. Brannen, S. Hudson Valley Food Hubs Initiative: Research Findings and Recommendations; Hudson Valley Pattern for Progress: Newburgh, NY, USA; Urban Design Lab at the Earth Institute, Columbia University: New York, NY, USA, 2013.

57. Rogoff, J. Improving Systems of Distribution and Logistics for Regional Food Hubs; The Central Appalachian Network: Abingdon, VA, USA; The Department of Urban Studies and Planning, Massachusetts Institute of Technology: Cambridge, MA, USA, 2014.

58. Goldsby, T.J.; Stank, T.P. World Class Logistics Performance and Environmentally Responsible Logistics Practices. J. Bus. Logist. 2000, 21, 187-208.

59. Blanchard, D. Supply Chain Management: Best Practices; John Wiley \& Sons: New York, NY, USA, 2010.

60. Sbihi, A.; Eglese, R.W. The Relationship between Vehicle Routing \& Scheduling and Green Logistics-A Literature Survey. 2007. Available online: https://hal.archives-ouvertes.fr/hal-00644133/document (accessed on 10 January 2018).

61. Jovičić, N.M.; Bošković, G.B.; Vujić, G.V.; Jovičić, G.R.; Despotović, M.Z.; Milovanović, D.M.; Gordić, D.R. Route Optimization to Increase Energy Efficiency and Reduce Fuel Consumption of Communal Vehicles. Therm. Sci. 2011, 14, S67-S78. [CrossRef]

62. Nuortio, T.; Kytöjoki, J.; Niska, H.; Bräysy, O. Improved Route Planning and Scheduling of Waste Collection and Transport. Expert Syst. Appl. 2006, 30, 223-232. [CrossRef]

63. Chopra, S. Designing the Distribution Network in a Supply Chain. Transp. Res. Part E Logist. Transp. Rev. 2003, 39, 123-140. [CrossRef]

64. Kant, G.; Jacks, M.; Aantjes, C. Coca-Cola Enterprises Optimizes Vehicle Routes for Efficient Product Delivery. Interfaces 2008, 38, 40-50. [CrossRef]

65. Ubeda, S.; Arcelus, F.J.; Faulin, J. Green Logistics at Eroski: A Case Study. Int. J. Prod. Econ. 2011, 131, 44-51. [CrossRef] 
66. Mckinnon, A. Sustainable Distribution: Opportunities to Improve Vehicle Loading. Ind. Environ. 2000, 23, 26-30.

67. Dejax, P.J.; Crainic, T.G. Survey Paper-A Review of Empty Flows and Fleet Management Models in Freight Transportation. Transp. Sci. 1987, 21, 227-248. [CrossRef]

68. Rizet, C.; Browne, M.; Cornelis, E.; Leonardi, J. Assessing Carbon Footprint and Energy Efficiency in Competing Supply Chains: Review-Case studies and Benchmarking. Transp. Res. Part D Transp. Environ. 2012, 17, 293-300. [CrossRef]

69. Jumadi, H.; Zailani, S. Integrating Green Innovations in Logistics Services Towards Logistics Service Sustainability: A Conceptual Paper. Environ. Res. J. 2010, 4, 261-271. [CrossRef]

70. Dasgupta, S.; Siddarth, S.; Silva-Risso, J. To Lease or to Buy? A Structural Model of a Consumer's Vehicle and Contract Choice Decisions. J. Mark. Res. 2007, 44, 490-502. [CrossRef]

71. Yurtkulu, E.Z.; Hilletofth, P.; Hilmola, O.P. Extended Service Use and New Product Possibilities in Swedish Trucking: Case Study. World Rev. Int. Transp. Res. 2014, 5, 80-98. [CrossRef]

72. Wagner, W.; Elam, R. Changing Environment of Truck Equipment Leasing. Transp. J. 1977, 16, 86-96.

73. Reibstein, D.J. What Attracts Customers to Online Stores, and What Keeps Them Coming Back? J. Acad. Market. Sci. 2002, 30, 465-473. [CrossRef]

74. Vogt, J.J. The Successful Cross-Dock Based Supply Chain. J. Bus. Logist. 2010, 31, 99-119. [CrossRef]

75. Kim, C.; Yang, K.H.; Kim, J. A Strategy for Third-party Logistics Systems: A Case Analysis Using the Blue Ocean Strategy. Omega 2008, 36, 522-534. [CrossRef]

76. Vaidyanathan, G. A Framework for Evaluating Third-Party Logistics. Commun. ACM 2005, 48, 89-94. [CrossRef]

77. CLECAT. Logistics Best Practice Guide; CLECAT-European Association for Forwarding, Transport, Logistics and Customs Services: Brussels, Belgium, 2010. Available online: https://www.clecat.org/media/ sr005osust101201clecatsustlogbpg2nded.pdf (accessed on 10 January 2018).

78. Chapman, R.L.; Soosay, C.; Kandampully, J. Innovation in Logistic Services and the New Business Model: A Conceptual Framework. Manag. Serv. Qual. 2002, 12, 358-371. [CrossRef]

79. Iannetta, M.; Giorgio, M.; Claudia, Z.; Stefano, C.; Lorenza, D.; Fabio, V.; Giovanna, Z. Innovation in Logistics and in the Supply Chain Integrated Approach. In Logistics and Agro-Food Trade: A Challenge for the Mediterranean; Presses de Sciences: Paris, France, 2014.

80. Ellram, L.M.; Cooper, M.C. Supply Chain Management, Partnership, and the Shipper-Third Party Relationship. Int. J. Logist. Manag. 1990, 1, 2-10. [CrossRef]

81. Audy, J.F.; Lehoux, N.; D'Amours, S.; Rönnqvist, M. A Framework for an Efficient Implementation of Logistics Collaborations. Int. Trans. Oper. Res. 2012, 19, 633-657. [CrossRef]

82. Mason, R.; Lalwani, C.; Boughton, R. Combining Vertical and Horizontal Collaboration for Transport Optimisation. Supply Chain Manag. Int. J. 2007, 12, 187-199. [CrossRef]

83. Barratt, M. Understanding the Meaning of Collaboration in the Supply Chain. Supply Chain Manag. Int. J. 2004, 9, 30-42. [CrossRef]

84. Sampson, S.E. Optimization of Volunteer Labor Assignments. J. Oper. Manag. 2006, 4, 363-377. [CrossRef]

85. Voss, M.D.; Calantone, R.J.; Keller, S.B. Internal Service Quality; Determinants of Distribution Center Performance. Int. J. Phys. Distrib. Logist. Manag. 2005, 35, 161-176. [CrossRef]

86. Cordery, J.L. Multi-skilling: A Discussion of Proposed Benefits of New Approaches to Labour Flexibility within Enterprises. Pers. Rev. 1989, 18, 13-22. [CrossRef]

87. Autry, C.W.; Daugherty, P.J. Warehouse Operations Employees: Linking Person-Organization Fit, Job Satisfaction, and Coping Responses. J. Bus. Logist. 2003, 24, 171-197. [CrossRef]

88. Daskin, M.S.; Snyder, L.V.; Berger, R.T. Facility Location in Supply Chain Design. Logist. Syst. Des. Optim. 2003, 3, 39-65.

89. Yang, J.; Lee, H. An AHP Decision Model for Facility Location Selection. Facilities 1997, 15, $241-254$. [CrossRef]

90. Nozick, L.K.; Turnquist, M.A. Inventory, Transportation, Service Quality and the Location of Distribution Centers. Eur. J. Oper. Res. 2001, 129, 362-371. [CrossRef]

91. Sahay, B.S.; Mohan, R. Supply Chain Management Practices in Indian Industry. Int. J. Phys. Distrib. Logist. Manag. 2003, 33, 582-606. [CrossRef] 
92. Van der Vorst, J.G.A.J.; Beulens, A.J.M.; de Wit, W.; van Beek, P. Supply Chain Management in Food Chains: Improving Performance by Reducing Uncertainty. Int. Trans. Oper. Res. 1998, 5, 487-499. [CrossRef]

93. Parfitt, J.; Barthel, M.; Macnaughton, S. Food Waste within Food Supply Chains: Quantification and Potential for Change to 2050. Philos. Trans. R. Soc. B Biol. Sci. 2010, 365, 3065-3081. [CrossRef] [PubMed]

94. Petersen, C.G.; Schmenner, R.W. An Evaluation of Routing and Volume-based Storage Policies in an Order Picking Operation. Decis. Sci. 1999, 30, 481-501. [CrossRef]

95. De Koster, R.; Le-Duc, T.; Roodbergen, K.J. Design and Control of Warehouse Order Picking: A Literature Review. Eur. J. Oper. Res. 2007, 182, 481-501. [CrossRef]

96. Routroy, S. Antecedents and Drivers for Green Supply Chain Management Implementation in Manufacturing Environment. ICFAI J. Supply Chain Manag. 2009, 6, 20-35.

97. Wu, H.; Dunn, S.C. Environmentally Responsible Logistics Systems. Int. J. Phys. Distrib. Logist. Manag. 1995, 25, 20-38. [CrossRef]

98. Caputo, M.; Mininno, V. Internal, Vertical and Horizontal Logistics Integration in Italian Grocery Distribution. Int. J. Phys. Distrib. Logist. Manag. 1996, 26, 64-90. [CrossRef]

99. Van Belle, J.; Valckenaers, P.; Cattrysse, D. Cross-docking: State of the Art. Omega 2012, 40, 827-846. [CrossRef]

100. Kinnear, E. Is there Any Magic in Cross-docking? Supply Chain Manag. Int. J. 1997, 2, 49-52. [CrossRef]

101. Apte, U.; Viswanathan, S. Effective Cross Docking for Improving Distribution Efficiencies. Int. J. Logist. Res. Appl. 2000, 3, 291-302. [CrossRef]

102. Folinas, D.; Manthou, V.; Sigala, M.; Vlachopoulou, M. E-volution of a Supply Chain: Cases and Best Practices. Internet Res. 2004, 14, 274-283. [CrossRef]

103. Opara, L.U. Traceability in Agriculture and Food Supply Chain: A Review of Basic Concepts, Technological Implications, and Future Prospects. Food Agric. Environ. 2003, 1, 101-106.

104. Kilger, C.; Wagner, M. Demand planning. In Supply Chain Management and Advanced Planning; Springer: Berlin, Germany, 2015; pp. 125-154.

105. Lee, H.L.; Whang, S. Information Sharing in a Supply Chain. Int. J. Manuf. Technol. 2000, 1, 79-93.

106. Fisher, M.; Krishnan, J.; Netessine, S. Retail Store Execution: An Empirical Study; The Wharton School, University of Pennsylvania: Philadelphia, PA, USA, 2006.

107. Selnes, F.; Gønhaug, K. Effects of Supplier Reliability and Benevolence in Business Marketing. J. Bus. Res. 2000, 49, 259-267. [CrossRef]

108. Liu, S.; So, K.C.; Zhang, F. Effect of Supply Reliability in a Retail Setting with Joint Marketing and Inventory Decisions. Manuf. Serv. Oper. Manag. 2010, 12, 19-32. [CrossRef]

109. Subirana, B.; Sarma, S.; Ferguson, C.; Langford, S.; Spears, S.; Jastremski, M.; Dubash, G.; Lee, J. EPC Changing the CPG Industry Improving Retail Promotional Execution; EPC Global White Paper: Lawrenceville, NJ, USA, 2006.

110. Stank, T.; Crum, M.; Arango, M. Benefits of Interfirm Coordination in Food Industry Supply Chains. J. Bus. Logist. 1999, 20, 21-42.

111. Fulk, J.; DeSanctis, G. Electronic Communication and Changing Organizational Forms. Organ. Sci. 1995, 6, 337-349. [CrossRef]

112. Kinsey, J.; Faster, A. Leaner, Supply Chain: New Uses of Information Technology. Am. J. Agric. Econ. 2000, 82, 1123-1129. [CrossRef]

113. Tranfield, D.; Denyer, D.; Smart, P. Towards a Methodology for Developing Evidence-Informed Management Knowledge by Means of Systematic Review. Br. J. Manag. 2003, 14, 207-222. [CrossRef]

114. Chadegani, A.A.; Salehi, H.; Yunus, M.M.; Farhadi, H.; Fooladi, M.; Farhadi, M.; Ebrahim, N.A. A Comparison Between Two Main Academic Literature Collections: Web of Science and Scopus Databases. Asian Soc. Sci. 2013, 9, 18-26. [CrossRef]

115. Mansouri, S.A.; Lee, H.; Aluko, O. Multi-objective Decision Support to Enhance Environmental Sustainability in Maritime Shipping: A Review and Future Directions. Transp. Res. Part E Logist. Transp. Rev. 2015, 78, 3-18. [CrossRef]

116. Ngai, E.W.T.; Moon, K.K.L.; Riggins, F.J.; Yi, C.Y. RFID Research: An Academic Literature Review (1995-2005) and Future Research Directions. Int. J. Prod. Econ. 2008, 112, 510-520. [CrossRef]

117. Chen, L.; Olhager, J.; Tang, O. Manufacturing Facility Location and Sustainability: A Literature Review and Research Agenda. Int. J. Prod. Econ. 2014, 149, 154-163. [CrossRef] 
118. Peterson, H.H.; Selfa, T.; Janke, R. Barriers and Opportunities for Sustainable Food Systems in Northeastern Kansas. Sustainability 2010, 2, 232-251. [CrossRef]

119. Happy Dancing Turtle. Central Minnesota Food Hub Feasibility Study; Happy Dancing Turtle: Pine River, MN, USA, 2012.

120. Brannen, S. Foodworks: A Vision to Improve NYC's Food System; The New York City Council: New York, NY, USA, 2010.

121. Doshi, S.; Nyquist, K.; Pirog, R.; Gerencer, M.; Bielaczyvc, N. Michigan Food Hub IT Platform Feasibility Study Public Summary; Michigan State University: East Lansing, MI, USA, 2015.

122. Tropp, D.; Ragland, E.; Barham, J. Supply Chain Basics: The Dynamics of Change in the U.S. Food Marketing Environment; United States Department of Agriculture: Washington, DC, USA, 2008.

123. Bittner, J.; Day-Farnsworth, L.; Miller, M.; Kozub, R.; Gollnik, B. Maximizing Freight Movements in Local Food Markets; National Center for Freight \& Infrastructure Research \& Education, University of Wisconsin-Madison: Madison, WI, USA, 2011.

124. Ochoa-Ortíz, A.; Ornelas-Zapata, F.; Margain-Fuentes, L.; Cedillo-Campos, M.G.; Sánchez-Aguilar, J.; Jaramillo-Vacio, R.; Ávila, I. Capacitated Vehicle Routing Problem for PSS Uses based on Ubiquitous Computing: An Emerging Markets Approach. DYNA 2015, 82, 20-26. [CrossRef]

125. Flaccavento, A. Healthy Food Systems: A Toolkit for Building Value Chains; The Central Appalachian Network: Abingdon, VA, USA, 2009.

126. Nelson, D.A.; Michelle, M.; Morales, A.; Zeitlow, B. Maximizing Freight Movements in Local Food Markets—Phase Two; National Center for Freight \& Infrastructure Research \& Education, University of Wisconsin-Madison: Madison, WI, USA, 2011.

127. Berney, G.; Tropp, D.; Clifton, K.; Mckenna, L. Delivering the Goods: Lessons Learned from Direct Delivery of Kentucky Catfish; United States Department of Agriculture: Washington, DC, USA, 2007.

128. Dreier, S.; Taheri, M. Innovative Models: Small Grower and Retailer Collaborations—Good Natured Family Farms and Balls Food Stores; Wallace Center at Winrock International: Arlington, VA, USA, 2008.

129. Horrell, C.; Jones, S.D.; Natelson, S.; Williams, K. An Investigation into the Workings of Small Scale Food Hubs; Sustain: The Alliance for Better Food and Farming: London, UK.

130. Joannides, J.; Turnquist, M.; Cureton, C.; Olson, B. Dodge County Food Hub Feasibility Study; Renewing the Countryside: Minneapolis, MN, USA, 2013.

131. Cantrell, P.; Heuer, B. Food Hubs: Solving Local: Small-Farm Aggregators Scale up with Larger Buyers; Wallace Center at Winrock International: Arlington, VA, USA, 2014.

132. Ostrom, M.; Stevenson, G.W. Values-Based Food Supply Chains: Full Circle; Center for Integrated Agricultural Systems, University of Wisconsin-Madison: Madison, WI, USA, 2013.

133. Diamond, A.; Barham, J. Moving Food Along the Value Chain: Innovations in Regional Food Distribution; United States Department of Agriculture: Washington, DC, USA, 2012.

134. Lyons, S.; McCann, N.; Wiemerslage, T.; Mabe, N. Developing a Worksite Food Box Program; Iowa State University Extension and Outreach: Ames, IA, USA; Leopold Center for Sustainable Agriculture: Ames, IA, USA, 2014.

135. Ellsworth, S.; Feenstra, G. Assessing the San Diego County Food System: Indicators for a More Food Secure Future; Agricultural Sustainability Institute, University of California, Davis: Davis, CA, USA, 2010.

136. Naskaris, S.; Pudukadan, R.; Smith, K.; Maher, M. Cost Analysis for a Cross Dock Alternative to Supply Local Produce from Food Hub to Grocery Store via a Large Regional Distribution Center; Center for Environmental Farming Systems, North Carolina State University: Raleigh, NC, USA, 2014.

137. Zajfen, V. Fresh Food Distribution Models for the Greater Los Angeles Region: Barriers and Opportunities to Facilitate and Scale up the Distribution of Fresh Fruits and Vegetables; Occidental College: Los Angeles, CA, USA, 2008.

138. Farnsworth, L.D.; McCown, B.; Miller, M.; Pfeiffer, A. Scaling up: Meeting the Demand for Local Food; Center for Integrated Agricultural Systems, University of Wisconsin-Madison: Madison, WI, USA; Agricultural Innovation Center, University of Wisconsin Cooperative Extension: Madison, WI, USA, 2009.

139. Matson, J.; Thayer, J.; Shaw, J. Running a Food Hub: Lessons Learned from the Field; United States Department of Agriculture: Washington, DC, USA, 2015.

140. Lindsey, T.; Slama, J. Building Successful Food Hubs: A Business Planning Guide for Aggregating and Processing Local Food in Illinois; Illinois Department of Commerce and Economic Opportunity: Springfield, IL, USA; 
University of Illinois Business Innovation Services: Naperville, IL, USA; Illinois Department of Agriculture: Springfield, IL, USA; FamilyFarmed: Chicago, IL, USA, 2012.

141. Matteson, G.; Shiflett, A. Buy vs. Lease Cost Comparison Tool. Available online: http://www.ngfn.org/ resources/ngfn-database/knowledge/BuyvsLeaseCostAnalysisandComparison.xlsx/view (accessed on 12 December 2017).

142. Derden-little, E.; Feenstra, G. An Evaluation of Capay Valley Grown: Report on the Findings from a Partner and Consumer Survey; Sustainable Agriculture Research \& Education Program, University of California, Davis: Davis, CA, USA, 2006.

143. Muldoon, M.F.; Taylor, A.; Richman, N.; Fisk, J. Innovations in Local Food Enterprise_Fresh Ideas for a Just and Profitable Food System; Wallace Center at Winrock International: Arlington, VA, USA, 2013.

144. Greenberg, L.S.Z. Innovative Strategies for Meeting New Markets; Cultural Landscape, LLC: Madison, WI, USA, 2007.

145. Fromartz, S. A New Kind of Middleman Is Helping Small Farmers Get Their Produce into Larger Stores-Without Sacrificing Quality or Income; Edible Portland Magazine: Portland, OR, USA, 2008.

146. Bachmann, J. Selling to Restaurants; National Center for Appropriate Technology: Butte, MT, USA, 2004.

147. Bellows, B.C.; Dufour, R.; Bachmann, J. Bringing Local Food to Local Institutions-A Resource Guide for Farm-To-School and Farm-To-Institution Programs; National Center for Appropriate Technology: Butte, MT, USA, 2003.

148. Common Market. The Common Market Feasibility Study. Available online: http://www.ngfn.org/ resources/ngfn-database/knowledge/Common\%20Market\%20Feasibility\%20Study.pdf (accessed on 10 January 2018).

149. Sachs, E.; Feenstra, G. Emerging Local Food Purchasing Initiatives in Northern California Hospitals; Agricultural Sustainability Institute, University of California, Davis: Davis, CA, USA, 2008.

150. Conner, D.S.; Sevoian, N.; Heiss, S.N.; Berlin, L. The Diverse Values and Motivations of Vermont Farm to Institution Supply Chain Actors. J. Agric. Environ. Ethics 2014, 27, 695-713. [CrossRef]

151. Schmidt, T.; Becca, J.; Kay, D. Assessing the Economic Impact of Regional Food hubs: The Case of Regional Access. Reg. Food 2015, 7, 956-963.

152. Sharma, A.; Moon, J.; Strohbehn, C. Restaurant's Decision to Purchase Local Foods: Influence of Value Chain Activities. Int. J. Hosp. Manag. 2014, 39, 130-143. [CrossRef]

153. Schweser, G.; Sisser, J. GROWN Locally: A Rural Food Hub in the Upper Midwest; University of Minnesota Extension: Saint Paul, MN, USA, 2013.

154. Van Dis, K. Central Oregon Food Hub Feasibility Study; Central Oregon Intergovernmental Council: Bend, OR, USA, 2012.

155. Parry, O.; Bussan, A.J.; Edgar, C.; Nyquist, K.; Slama, J. Southern Wisconsin Food Hub Feasibility Study; Dane County Planning and Development Department: Madison, WI, USA, 2011.

156. Clark, J.K.; Inwood, S.; Sharp, J. Scaling-Up Connections between Regional Ohio Specialty Crop Producers and Local Markets: Distribution as the Missing Link; Department of Agricultural, Environmental, and Developmental Economics, The Ohio State University: Columbus, OH, USA, 2011.

157. Cech, S. California Network of Regional Food Hubs: A Vision Statement and Strategic Implementation; Urban and Environmental Policy Institute: Los Angeles, CA, USA, 2010.

158. Stevenson, G.W. Values-Based Food Supply Chains: Good Earth Farms; Center for Integrated Agricultural Systems, University of Wisconsin-Madison: Madison, WI, USA, 2013.

159. Stevenson, G.W. Values-Based Food Supply Chains: Organic Valley; Center for Integrated Agricultural Systems, University of Wisconsin-Madison: Madison, WI, USA, 2013.

160. Barham, J.; Delgado, F. Building A Food Hub from the Ground up: A Facility Design Case Study of Tuscarora Organic Growers; United States Department of Agriculture: Washington, DC, USA, 2015.

161. King, R.P.; Stevenson, G.W. Values-Based Food Supply Chains: Co-Op Partners Warehouse; Center for Integrated Agricultural Systems, University of Wisconsin-Madison: Madison, WI, USA, 2013.

162. Cantrell, P. Sysco's Journey from Supply Chain to Value Chain: 2008-2009 Final Report; Wallace Center at Winrock International: Arlington, VA, USA, 2010.

163. Frain, M. The ABCs of Marketing to Restaurants; Rodale Institute: Kutztown, PA, USA, 2002.

164. Pirog, R. Institutional Buying Models and Local Food Markets: The Iowa Experience; Leopold Center for Sustainable Agriculture: Ames, IA, USA, 2002. 
165. Chiffoleau, Y. From Politics to Co-operation: The Dynamics of Embeddedness in Alternative Food Supply Chains. Sociol. Rural 2009, 49, 218-235. [CrossRef]

166. Warshawer, S. Farmer's Guide to On-Farm Food Safety Certification; Wallace Center at Winrock International: Arlington, VA, USA, 2013.

167. Berkenkamp, J. Eating Our Peas \& Carrots: Strategies for Expanding K-12 Access to Fruits and Vegetables through Supply Chain Innovation and Investment; Tomorrow's Table, LLC: Minneapolis, MN, USA, 2014.

168. Kline, C.S.; Joyner, L.E.; Kirchoff, J.F.; Crawford, A.; Pitts, S.J.; Wall-Bassett, E.; Gurganus, C.; Dunning, R. Gaps and Barriers along the North Carolina Agri-food Value Chain. Br. Food J. 2016, 118, 301-317. [CrossRef]

169. Amanor-Boadu, V.R.; Marletta, P.; Biere, A. Entrepreneurial Supply Chains and Strategic Collaboration: The case of Bagòss Cheese in Bagolino, Italy. Int. Food Agribus. Manag. Rev. 2009, 12, 49-68.

170. Pirog, R.; Bregendahl, C. Creating Change in the Food System: The Role of Regional Food Networks in Iowa; Center for Regional Food Systems, Michigan State University: East Lansing, MI, USA, 2012.

171. Fanatico, A. Beef Marketing Alternatives; National Center for Appropriate Technology: Butte, MT, USA, 2006.

172. Gorton, M.; White, J. The Restructuring of Agri-food Supply Chains in CEE and the CIS: Overview and Policy Implications. Outlook Agric. 2007, 36, 237-246. [CrossRef]

173. Bloom, J.D.; Hinrichs, C.C. Moving Local Food through Conventional Food System Infrastructure: Value Chain Framework Comparisons and Insights. Renew. Agric. Food Syst. 2011, 26, 13-23. [CrossRef]

174. Diamond, A.; Tropp, D.; Barham, J.; Muldoon, M.F.; Kiraly, S.; Cantrell, P. Food Value Chains: Creating Shared Value to Enhance Marketing Success; United States Department of Agriculture: Washington, DC, USA, 2014.

175. Pirog, R.S.; Larabee, B.E.; Robertson, M.; Huber, G.; Larson, A. Making Value Chains Work: Best Practices for Success_-Workshop Proceedings; Leopold Center for Sustainable Agriculture: Ames, IA, USA, 2008.

176. Dreier, S.; Taheri, M. Innovative Models: Small Grower and Retailer Collaborations: Part B-Balls Food Stores' Perspective; Wallace Center at Winrock International: Arlington, VA, USA, 2009.

177. Pan, S.; Ballot, E.; Fontane, F.; Hakimi, D. Environmental and Economic Issues Arising from the Pooling of SMEs' Supply Chains: Case study of the Food Industry in Western France. Flex. Serv. Manuf. J. 2014, 26, 92-118. [CrossRef]

178. Fisk, J.; Matteson, G. Counting Values Food Hub Financial Benchmarking Study; Farm Credit East: Enfield, CT, USA; Wallace Center at Winrock International: Arlington, VA, USA; Morse Marketing Connections, LLC: Norton Shores, MI, USA; The Farm Credit Council: Washington, DC, USA, 2015.

179. Slama, J.; Nyquist, K.; Bucknum, M. Local Food System Assessment for Northern Virginia; Family Farmed: Chicago, IL, USA; Wallace Center at Winrock International: Arlington, VA, USA; Triskeles Foundation: Exton, PA, USA, 2010.

180. Morley, A.; Morgan, S.; Morgan, K. Food Hubs: The 'Missing Middle' of the Local Food Infrastructure? Brass Center, Cardiff University: Cardiff, UK, 2008.

181. Moraghan, M.R.; Vanderburgh-Wertz, D. Food Hub Business Assessment Toolkit; Wholesome Wave: Bridgeport, CT, USA, 2014.

182. Etemadnia, H.; Goetz, S.J.; Canning, P.; Tavallali, M.S. Optimal Wholesale Facilities Location within the Fruit and Vegetables Supply Chain with Bimodal Transportation Options: An LP-MIP Heuristic Approach. Eur. J. Oper. Res. 2015, 244, 648-661. [CrossRef]

183. Bourlakis, M.; Maglaras, G.; Aktas, E.; Gallear, D.; Fotopoulos, C. Firm Size and Sustainable Performance in Food Supply Chains: Insights from Greek SMEs. Int. J. Prod. Econ. 2014, 152, 112-130. [CrossRef]

184. Grajewski, G.; Berney, G. Supply Chain Basics Technology—How Much, How Soon; United States Department of Agriculture: Washington, DC, USA, 2007.

185. Hardesty, S. Values-Based Supply Chains: Supporting Regional Food and Farms. Econ. Dev. Q. 2014, 28, 17-27. [CrossRef]

186. Forssell, S.; Lankoski, L. The Sustainability Promise of Alternative Food Networks: An Examination through 'alternative' Characteristics. Agric. Hum. Values 2014, 32, 63-75. [CrossRef]

187. Atasoy, Y. Supermarket Expansion in Turkey: Shifting Relations of Food Provisioning. J. Agrar. Chang. 2013, 13, 547-570. [CrossRef]

188. Sherwood, D.; Kiraly, S.; Singleton, K. Deep South Local and Regional Food Systems Resources for Farmers, Aggregators and Distributors; Wallace Center at Winrock International: Arlington, VA, USA, 2014.

189. Jewett, J.G.; Nelson, B.; Braaten, D. Marketing Local Food; Minnesota Institute for Sustainable Agriculture: Falcon Heights, MN, USA, 2007. 
190. Lerman, T.; Feenstra, G.; Visher, D. Food Hubs and Values-Based Supply Chains: A Toolkit for California Farmers and Ranchers Food Hubs and Values-Based Supply Chains; Agricultural Sustainability Institute, University of California, Davis: Davis, CA, USA, 2012.

191. Berney, G.; Grajewski, G.; Hinman, D.; Prater, M.; Taylor, A. Marketing Maine Tabelstock Potatoes; United States Department of Agriculture: Washington, DC, USA, 2010.

192. Ingels, C.; Sowerwine, J. Final Report Expanding Regional Markets for Southeast Asian and Other Small Farmers in Sacramento: Linking Farmers, Processors and Buyers; University of California Cooperative Extension: Sacramento County, CA, USA, 2012.

193. Battini, D.; Calzavara, M.; Persona, A.; Sgarbossa, F. Sustainable Packaging Development for Fresh Food Supply Chains. Packag. Technol. Sci. 2016, 29, 25-43. [CrossRef]

194. Accorsi, R.; Cascini, A.; Cholette, S.; Manzini, R.; Mora, C. Economic and Environmental Assessment of Reusable Plastic Containers: A Food Catering Supply Chain Case Study. Int. J. Prod. Econ. 2014, 152, 88-101. [CrossRef]

195. Sullivan, D. Internet Buying Clubs Combine Emerging Technologies and Community Values; Rodale Institute: Kutztown, PA, USA, 2005.

196. Matson, J.; Cook, C.; Sullins, M. The Role of Food Hubs in Local Food Marketing; United States Department of Agriculture: Washington, DC, USA, 2013.

197. Curtis, J.; Creamer, N.; Thraves, T.E. From Farm to Fork: A Guide to Building North Carolina's Sustainable Local Food Economy; Center for Environmental Farming Systems, North Carolina State University: Raleigh, NC, USA, 2010.

198. Ryan, J.J. Great Falls Food Hub Feasibility Assessment; Development Cycles: Montpelier, VT, USA, 2011.

199. Dervillé, M.; Allaire, G. Change of Competition Regime and Regional Innovative Capacities: Evidence from Dairy Restructuring in France. Food Policy 2014, 49, 347-360. [CrossRef]

200. Aubry, C.; Kebir, L. Shortening Food Supply Chains: A Means for Maintaining Agriculture Close to Urban Areas? The Case of the French Metropolitan Area of Paris. Food Policy 2013, 41, 85-93. [CrossRef]

201. Pirog, R.; Harper, A.; Gerencer, M.; Lelle, M.; Gerencer, C. The Michigan Food Hub Network: A Case Study in Building Effective Networks for Food System Change; Center for Regional Food Systems, Michigan State University: East Lansing, MI, USA, 2014.

202. Hamilton, K.; Howie, K.; Wagner, C. Siting and Cost Analysis for a Cross Dock Consolidation Center for Local Produce; Center for Environmental Farming Systems, North Carolina State University: Raleigh, NC, USA, 2014.

203. Barry, J.; Pirog, R. Supplying Local and Regional Markets: Challenges and Solutions for the Michigan-Based Meat and Livestock Value Chains; Center for Regional Food Systems, Michigan State University: East Lansing, MI, USA, 2013.

204. Doshi, S.; Isaacman-VanWertz, D.; Moraghan, M.R. Tech Guide for Food Hubs: Making Technology Work for You; New Venture Advisors: Chicago, IL, USA; Wholesome Wave: Bridgeport, CT, USA.

205. Ennis, J. Characterizing Optimal Business Conditions for Commerce Between Farmers and SYSCO_Phase Two; Cooperative Development Services: Saint Paul, MN, USA, 2006.

206. Marshall, C.; Feenstra, G.; Zajfen, V. Increasing Access to Fresh, Local Produce: Building Values-Based Supply Chains in San Diego Unified School District. Child. Obes. 2012, 8, 388-391. [CrossRef] [PubMed]

207. Gegner, L. Pork: Marketing Alternatives; National Center for Appropriate Technology: Butte, MT, USA, 2004.

208. Feenstra, G.; Visher, D.; Hardesty, S. Developing Values Based Distribution Networks to Enhance the Prosperity of Small and Medium Sized Producers: Full Study; Agricultural Sustainability Institute, University of California, Davis: Davis, CA, USA, 2011.

209. Derden-Little, E.; Feenstra, G. Regional Agricultural Marketing: A Review of Programs in California; Sustainable Agriculture Research \& Education Program, University of California, Davis: Davis, CA, USA, 2006.

210. Williams, J. Authenticity and Success in Marketing 'Local' in Retail Grocery Settings; Center for Environmental Farming Systems, North Carolina State University: Raleigh, NC, USA.

211. Wallace Center at Winrock International. Getting Started with Farmers Markets; Wallace Center at Winrock International: Arlington, VA, USA.

212. Pakurár, M.; Kovács, S.; Popp, J.; Vántus, A. Innovative Solutions in Traceability to Improve the Competitiveness of a Local Fruit and Vegetable Retailing System. Amfiteatru Econ. 2015, 17, 676-692.

213. Kim, E.; Kurlanski, M. Snapshot Series: Transitioning to Value Added Enterprises; Wallace Center at Winrock International: Arlington, VA, USA, 2010. 
214. Ringsberg, H.A. Implementation of Global Traceability Standards: Incentives and Opportunities. Br. Food J. 2015, 117, 1826-1842. [CrossRef]

215. Manos, B.; Manikas, I. Traceability in the Greek Fresh Produce Sector: Drivers and Constraints. Br. Food J. 2010, 112, 640-652. [CrossRef]

216. Lyons, S.M. Using Accounting Software for Food Hubs: Processing Traceable Orders; Iowa State University Extension and Outreach: Ames, IA, USA, 2015.

217. Tedeschi, S. Growing Farm to School Supply Chains with Local Vegetable Blends; Center for Integrated Agricultural Systems, University of Wisconsin-Madison: Madison, WI, USA, 2014.

218. Kirschenmann, F. A Pig's Tale: Marketing Stories for New Value Chains; Leopold Center for Sustainable Agriculture: Ames, IA, USA.

219. Lyons, S.M.; Oldham, M. Production Planning for Aggregators; Leopold Center for Sustainable Agriculture: Ames, IA, USA, 2014.

220. Wallace Center at Winrock International. Farmers Market Managers Frequently Asked Questions; Wallace Center at Winrock International: Arlington, VA, USA, 2010.

221. Riordan, M. Overcoming Obstacles to Local Frozen Produce: Matching Production Mode to Market Niche; Common Market: Philadelphia, PA, USA, 2014.

222. Stevenson, G.W.; Larry, L. Values-based Food Supply Chains: Country Natural Beef; Center for Integrated Agricultural Systems, University of Wisconsin-Madison: Madison, WI, USA, 2013.

223. Sayre, L. The Whole(sale) Deal; Rodale Institute: Kutztown, PA, USA, 2005.

224. Marshall, C.; Feenstra, G. San Diego Unified School District Farm to School Evaluation; Agricultural Sustainability Institute, University of California, Davis: Davis, CA, USA, 2012.

225. Abate, G. Local Food Economies: Driving Forces, Challenges, and Future Prospects. J. Hunger Environ. Nutr. 2008, 3, 384-399. [CrossRef]

226. National Good Food Network. Food Hub Benchmarking Study: Report on Findings 2013; Wallace Center at Winrock International: Arlington, VA, USA; Farm Credit East: Enfield, CT, USA; The Farm Credit Council: Washington, DC, USA; Morse Marketing Connections, LLC: Norton Shores, MI, USA, 2013.

227. Conner, D.S.; Knudson, W.A.; Hamm, M.W.; Peterson, H.C. The Food System as an Economic Driver: Strategies and Applications for Michigan. J. Hunger Environ. Nutr. 2008, 3, 371-383. [CrossRef]

228. Azzarello, M.; Franklin, S.; McKoy, B.; Capece, A.; Jensen, J.; Sarsycki, M.; Cassidy, M.; Joiner, E.; Scott, D.; Chamberlain, L.; et al. Community Economic Development Impacts of the Rutgers Food Innovation Center; Edward J. Bloustein School of Planning and Public Policy, Rutgers University: New Brunswick, NJ, USA, 2012.

229. Stevenson, G.W. Values Based Food Supply Chains: Idaho's Bounty; Center for Integrated Agricultural Systems, University of Wisconsin-Madison: Madison, WI, USA, 2013.

230. Niche Meat Processor Assistance Network. Good Natured Family Farms Meat Processing Plant; eXtension Foundation: Kansas City, MO, USA, 2008.

231. Bauer, L.; Berton, V. Banding Together to Build an Alternative Meat Market; Rodale Institute: Kutztown, PA, USA, 2003.

232. Shuman, M.; Barron, A.; Wasserman, W. Community Food Enterprise: Local Success in a Global Marketplace; Wallace Center at Winrock International: Arlington, VA, USA; Business Alliance for Local Living Economies: Oakland, CA, USA, 2009.

233. Mccann, N.; Lyons, S.M.; Artz, G.M. Managing Cash Flow for a Low-Capital Food Hub Start-Up; Iowa State University Extension and Outreach: Ames, IA, USA; Leopold Center for Sustainable Agriculture: Ames, IA, USA, 2015.

234. Feldstein, S.; Barham, J. Running a Food Hub: Learning from Food Hub Closures; United States Department of Agriculture: Washington, DC, USA, 2017.

235. Matopoulos, A.; Vlachopoulou, M.; Manthou, V.; Manos, B. A Conceptual Framework for Supply Chain Collaboration: Empirical Evidence from the Agri-food Industry. Supply Chain Manag. Int. J. 2007, 12, 177-186. [CrossRef]

236. Krejci, C.C.; Dorneich, M.C.; Stone, R.T. Assessing Values-Based Sourcing Strategies in Regional Food Supply Networks: An Agent-Based Approach. J. Policy Complex Syst. 2015, 2, 21-48. [CrossRef]

237. Berti, G.; Mulligan, C. Competitiveness of Small Farms and Innovative Food Supply Chains: The Role of Food Hubs in Creating Sustainable Regional and Local Food Systems. Sustainability 2016, 8, 616. [CrossRef] 
238. Craven, T.; Mittal, A.; Krejci, C.C. Effective Coordination in Regional Food Supply Chains. In Proceedings of the Industrial and Systems Engineering Research Conference, Anaheim, CA, USA, 21-24 May 2016.

239. Mittal, A.; Zugg, M.; Krejci, C.C. Improving Regional Food Hub Operational Efficiency with Lean Practices. In Proceedings of the Industrial and Systems Engineering Research Conference, Anaheim, CA, USA, 21-24 May 2016.

240. Mittal, A.; White, V.; Krejci, C.C. A Framework for Collaboration among Regional Food System Participants. In Proceedings of the Industrial and Systems Engineering Conference, Pittsburgh, PA, USA, 20-23 May 2017.

241. Mittal, A.; Krejci, C.C. A Hybrid Simulation Model of Inbound Logistics Operations in Regional Food Supply Systems. In Proceedings of the Winter Simulation Conference, Huntington Beach, CA, USA, 6-9 December 2015; pp. 1549-1560.

242. Mittal, A. Hybrid Simulation Modeling for Regional Food Systems; Iowa State University: Ames, IA, USA, 2016.

243. Mittal, A.; Krejci, C.C. A Hybrid Simulation Modeling Framework for Regional Food Hubs. J. Simul. 2017. Available online: https:/ /link.springer.com/article/10.1057/s41273-017-0063-z (accessed on 10 January 2018). [CrossRef]

(C) 2018 by the authors. Licensee MDPI, Basel, Switzerland. This article is an open access article distributed under the terms and conditions of the Creative Commons Attribution (CC BY) license (http:/ / creativecommons.org/licenses/by/4.0/). 